\title{
Low temperature IR spectroscopy and photochemistry of matrix-isolated $\alpha$-pyridil
}

\author{
Susy Lopes ${ }^{\mathrm{a}}$, Andrea Gómez-Zavaglia ${ }^{\mathrm{a}, \mathrm{b}}$, Rui Fausto ${ }^{\mathrm{a}, *}$ \\ a Department of Chemistry, University of Coimbra, P-3004-535 Coimbra, Portugal \\ b Faculdad de Farmacia y Bioquímica, Universidad de Buenos Aires, Junín 956, 1113 Buenos Aires, Argentina
}

\section{A R T I C L E I N F O}

\section{Article history:}

Received 30 May 2008

Received in revised form 3 July 2008

Accepted 8 July 2008

Available online 18 July 2008

\section{Keywords:}

$\alpha$-Pyridil

Matrix isolation

FTIR spectroscopy

Low temperature solid state

DFT(B3LYP)/6-311++G(d,p) calculations

Conformational analysis

Photochemistry

Hückel pyridine

\begin{abstract}
A B S T R A C T
$\alpha$-Pyridil $\left[\left(\mathrm{C}_{6} \mathrm{H}_{4} \mathrm{NO}\right)_{2}\right]$ has been isolated in low temperature argon and xenon matrices and studied by FTIR spectroscopy, supported by DFT(B3LYP)/6-311++G(d,p) calculations. Calculations predicted the existence of three different conformers exhibiting skewed conformations around the intercarbonyl bond and the two $\mathrm{C}_{5} \mathrm{H}_{4} \mathrm{~N}-\mathrm{C}(=\mathrm{O})$ fragments nearly planar. The two higher energy forms, $\boldsymbol{T C G}$ and $\boldsymbol{C C S k}$ were estimated theoretically to be, respectively, 21.0 and $35.1 \mathrm{~kJ} \mathrm{~mol}^{-1}$ higher in energy than the most stable form, TTG. In consonance with the relatively high energies predicted by the calculations for the two less stable conformers of $\alpha$-pyridil, only the most stable conformer was found spectroscopically to be present in the studied matrices. Infrared spectra obtained for the neat low temperature amorphous and crystalline states reveals that the TTG conformer is also the sole conformer present in these phases. UV irradiation $(\lambda>235 \mathrm{~nm})$ of matrix-isolated $\alpha$-pyridil led to its isomerization into unusual molecular species bearing Hückel-type pyridine (aza-benzvalene) rings.
\end{abstract}

(c) 2008 Elsevier B.V. All rights reserved.

\section{Introduction}

In general, simple $\alpha$-dicarbonyl compounds show interesting structural, spectroscopic and photophysical properties, including photorotamerism, due to conformational changes associated with the internal rotation around the flexible $\mathrm{O}=\mathrm{C}-\mathrm{C}=\mathrm{O}$ intercarbonyl torsional coordinate in the ground or excited electronic states [1-8]. Because of that, these compounds have received particular attention concerning their potential use for the development of molecular devices [9-14]. These compounds have also received application in other fields. For example, derivatives of $\alpha$-pyridil $\left[\mathrm{C}_{6} \mathrm{NH}_{4}-\mathrm{C}(=\mathrm{O})-\mathrm{C}(=\mathrm{O})-\mathrm{C}_{6} \mathrm{NH}_{4}\right]$, which is a typical representative of aromatic heterocyclic $\alpha$-dicarbonyls are main components of many pesticides, herbicides and fungicides [15-17] and have been used as reagents in the production of several compounds with pharmaceutical interest [18-21]. $\alpha$-Pyridils have also found important applications in the preparation of transition metal complexes [22-24] and as organic inhibitors for mild steel corrosion in hydrochloric acid [25].

\footnotetext{
* Corresponding author. Tel.: +351 239 852080; fax: +351 239827703.

E-mail address: rfausto@ci.uc.pt (R. Fausto).
}

The crystal structure of $\alpha$-pyridil has already been determined by X-ray crystallography $[26,27]$. It crystallizes in the monoclinic system, space group $P 2_{1} / n$, with four molecules per unit cell. In the crystal, the molecule is known to adopt a structure in which two nearly planar fragments, each of which including a pyridine ring, a carbonyl group and its adjacent carbon atom, are skewed to each other, the angle between the two pyridyl fragments being $\mathrm{ca} .83^{\circ}$. The predominant forces gathering the molecules in the crystal were found to be plane-to-plane interactions between approximately parallel pyridine rings [26,27].

$\alpha$-Pyridil was also studied in the past by FT-IR, Raman, NMR and UV spectroscopies in the solid state and in solution either in the ground or in the excited states [28-40]. Some of these studies addressed the question of the conformational preferences of this molecule [28,33-40].

As in other $\alpha$-dicarbonyl compounds, the geometry of $\alpha$-pyridil is the result of a balance between steric and resonance effects and seem to be different in different electronic states. The conjugation of the carbonyl groups with the pyridyl rings would favor the planar molecular configurations in order to achieve maximum $\pi$ overlap, but the steric repulsions between the carbonyl oxygens, between these atoms and the nearest hydrogen atoms of the pyridyl rings and between the two pyridyl substituents preferably twist the whole molecule, making skewed structures to be more stable than 
the planar ones in the electronic ground state. Investigations carried out for the compound in different solutions $[28,33,40]$ indicated that in these media the compound exists in a single conformation similar to that observed in the crystal, with the intercarbonyl angle decreasing with the increase in polarity of the solvent [33]. On the other hand, according to time-resolved transient absorption spectra measurements, the lowest energy triplet state of $\alpha$-pyridil seems to be planar in non-polar solvents [41].

To the best of our knowledge, no structural or vibrational studies have been performed on gaseous $\alpha$-pyridil as well as for the compound isolated in a low temperature inert matrix hitherto. In addition, its photochemistry has also been addressed only for the compound in solution [36,37,41], where the media was found to play an active role, such as, for example, as source of hydrogen atoms in the photochemical reduction of $\alpha$-pyridil into the enediol, 1,2-di(2-pyridyl)-1,2-ethenediol.

In the present work, the conformational study of the molecule of $\alpha$-pyridil was undertaken using low-temperature matrix-isolation FTIR spectroscopy combined with theoretical calculations preformed at the DFT(B3LYP)/6-311++G(d,p) level of theory. These studies allowed for the identification and vibrational characterization of the most stable conformer of $\alpha$-pyridil. Irradiation of matrix-isolated $\alpha$-pyridil with UV light $(\lambda>235 \mathrm{~nm})$ was also carried out in order to study its unimolecular photochemistry. As it will be described in detail below, under these experimental conditions $\alpha$-pyridil isomerizes to molecular species bearing Hückel-type pyridyl (aza-benzvalene) substituents. Finally, low temperature infrared spectra of neat $\alpha$-pyridil in the amorphous and crystalline states were also obtained and interpreted.

\section{Materials and methods}

\subsection{Infrared spectroscopy}

The sample of $\alpha$-pyridil (97\% purity) was obtained from Aldrich and used without any further purification.

The IR spectra were recorded with $0.5 \mathrm{~cm}^{-1}$ spectral resolution in a Mattson (Infinity 60AR Series) Fourier Transform infrared spectrometer, equipped with a deuterated triglycine sulphate (DTGS) detector and a $\mathrm{Ge} / \mathrm{KBr}$ beam splitter. Necessary modifications of the sample compartment of the spectrometer were done in order to accommodate the cryostat head and allow purging of the instrument by a stream of dry nitrogen, to remove water vapors and $\mathrm{CO}_{2}$. The solid sample of $\alpha$-pyridil was placed in a specially designed thermoelectrically heatable mini-furnace assembled within the cryostat chamber. The temperatures of sublimation of the compound under these conditions varied within the $80-125^{\circ} \mathrm{C}$ range. Matrices were prepared by co-deposition of $\alpha$-pyridil vapors coming out of the mini-furnace and large excess of the matrix gas (argon N60 or xenon N48, both obtained from Air Liquide) onto the CSI substrate of the cryostat (APD Cryogenics, model DE$202 \mathrm{~A}$ ), cooled to $10 \mathrm{~K}$ (for argon matrices) or $20 \mathrm{~K}$ (for xenon matrices).

Irradiation of the matrices was carried out with unfiltered light from a $500 \mathrm{~W} \mathrm{Hg}(\mathrm{Xe})$ lamp (Newport, Oriel Instruments), with output power set to $200 \mathrm{~W}$, through the outer $\mathrm{KBr}$ windows of the cryostat $(\lambda>235 \mathrm{~nm})$.

The low temperature solid amorphous layer of $\alpha$-pyridil was prepared in the same way as matrices but with the flux of matrix gas cut off. The layer was then allowed to anneal at slowly increasing temperature up to $300 \mathrm{~K}$. After the temperature exceeded $250 \mathrm{~K}$ the crystallization of the amorphous layer occurred. Subsequently, the sample was cooled back to $10 \mathrm{~K}$ and the spectrum of the crystalline phase was collected.

\subsection{Computational methodology}

The quantum chemical calculations were performed with Gaussian 03 (Revision C.02) [42] at the DFT level of theory, using the split valence triple- $\zeta 6-311++G(d, p)$ basis set and the three-parameter B3LYP density functional, which includes Becke's gradient exchange correction [43] and the Lee, Yang and Parr correlation functional [44].

Geometrical parameters of the considered conformations were optimized using the Geometry Direct Inversion of the Invariant Subspace (GDIIS) method [45]. In order to assist the analysis of the experimental spectra, vibrational frequencies and IR intensities were also calculated at the same level of approximation. The computed harmonic frequencies were scaled down by a single factor $(0.978)$ to correct them for the effects of basis set limitations, neglected part of electron correlation and anharmonicity effects. Normal coordinate calculations were undertaken in the internal coordinates space, as described by Schachtschneider [46], using the program BALGA and the optimized geometries and harmonic force constants resulting from the DFT calculations.

\section{Results and discussion}

\subsection{Geometries and energies}

The DFT(B3LYP)/6-311++G(d,p) calculations performed in this study predicted the existence of three non-symmetricallyequivalent minima on the potential energy surface of $\alpha$-pyridil. These structures are displayed in Fig. 1 and exhibit a skewed conformation around the intercarbonyl bond and the two $\mathrm{C}_{5} \mathrm{H}_{4} \mathrm{~N}-\mathrm{C}(=\mathrm{O})$ fragments nearly planar. The names here adopted to designate the different conformers are based on the values of the $\mathrm{O}=\mathrm{C}-\mathrm{C}-\mathrm{N}$ and $\mathrm{O}=\mathrm{C}-\mathrm{C}=\mathrm{O}$ dihedral angles, where $\boldsymbol{T}, \boldsymbol{C}, \boldsymbol{G}$ and $\boldsymbol{S} \boldsymbol{k}$ refer to values of these angles of $\mathrm{ca} .180^{\circ}$ (trans), $0^{\circ}$ (cis), $90^{\circ}$ (gauche) and $120^{\circ}$ (skew). The two most stable forms have the $\mathrm{O}=\mathrm{C}-\mathrm{C}=\mathrm{O}$ moiety in the gauche configuration: TTG, with $\mathrm{C}_{2}$ symmetry and the $\mathrm{O}=\mathrm{C}-\mathrm{C}=\mathrm{O}$ intercarbonyl dihedral angle equal to $82.3^{\circ}$, and TCG, with $C_{1}$ symmetry and the intercarbonyl dihedral angle equal to $102.1^{\circ}$. In the less stable form, $\boldsymbol{C C S k}$ ( $\mathrm{C}_{2}$ symmetry), the $\mathrm{O}=\mathrm{C}-\mathrm{C}=\mathrm{O}$ dihedral angle is $118.3^{\circ}$ (skew). The three conformers differ in the orientation of the pyridyl rings relatively to the carbonyl groups. In the most stable conformer (TTG) both pyridyl rings adopt the trans orientation relatively to the nearest carbonyl group, the $\mathrm{CH}$. . O distance in the two $\mathrm{H}-\mathrm{C}=\mathrm{C}-\mathrm{C}=\mathrm{O}$ five-membered rings being $259.2 \mathrm{pm}$. The second most stable conformer (TCG) has one pyridyl ring orientated that way, while the other is rotated by $c a .180^{\circ}$, resulting in an energetically less favorable $\mathrm{H} 24-\mathrm{C} 16=\mathrm{C} 6-\mathrm{C} 3-\mathrm{C} 1=\mathrm{O} 2$ six-membered ring. In this conformer, the calculated $\mathrm{CH}$... O distances are 268.5 and $261.2 \mathrm{pm}$, for the six and five-membered ring, respectively. Finally, in the third conformer both pyridyl rings are in the cis orientation with respect to the carbonyl groups, forming two $\mathrm{H}-\mathrm{C}=\mathrm{C}-\mathrm{C}-\mathrm{C}=\mathrm{O}$ six-membered rings where the $\mathrm{CH}$.. O distance is $244.2 \mathrm{pm}$. The theoretical calculations predicted the two higher energy forms to be respectively 21.0 and $35.1 \mathrm{~kJ} \mathrm{~mol}^{-1}$ higher in energy than the TTG form.

The calculated geometries for all three conformers of $\alpha$-pyridil are given in Table S1 (Supplementary Material), together with the geometry of the molecular unit in the crystal of the compound previously obtained by X-ray diffraction, which corresponds to a conformation similar to the TTG conformer, but slightly distorted from the $C_{2}$ symmetry [27]. The experimental parameters obtained by X-ray diffraction and those calculated for the isolated TTG conformer show a fairly good agreement, indicating that the crystal packing forces do not introduce substantial geometrical con- 


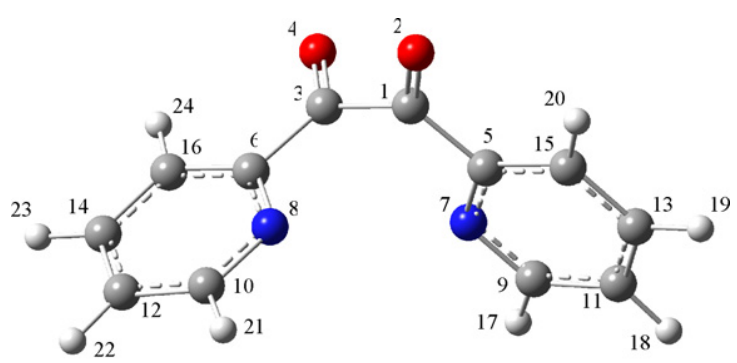

$\operatorname{TTG}\left(\mathrm{C}_{2}\right)$

$\mathrm{E}=0.0 \mathrm{~kJ} \mathrm{~mol}^{-1} ; \mu=4.94 \mathrm{D}$

$\left(180.0,180.0,82.3^{\circ}\right)$

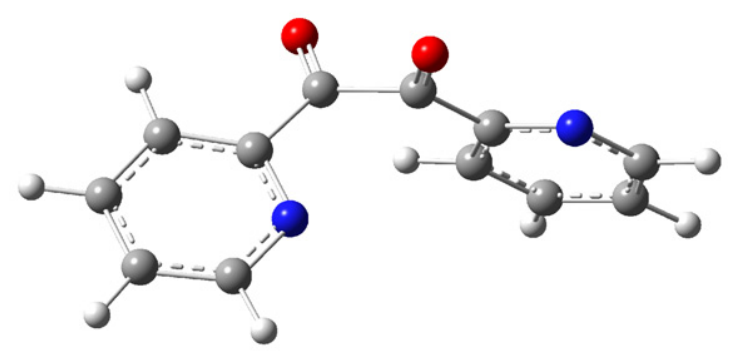

$\operatorname{TCG}\left(\mathrm{C}_{1}\right)$

$\Delta \mathrm{E}=21.0 \mathrm{~kJ} \mathrm{~mol}^{-1} ; \mu=5.56 \mathrm{D}$

$\left(164.7,6.0,102.1^{\circ}\right)$

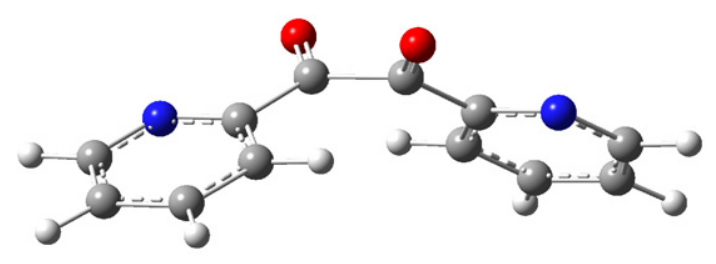

$\operatorname{ccsk}\left(\mathrm{C}_{2}\right)$

$\Delta \mathrm{E}=35.1 \mathrm{~kJ} \mathrm{~mol}^{-1} ; \mu=4.90 \mathrm{D}$

$\left(5.2,5.2,118.3^{\circ}\right)$

Fig. 1. Conformers of $\alpha$-pyridil, with atom numbering. Calculated relative energies and dipole moments of the conformers are also provided, as well as the values of their defining dihedral angles $\left(\mathrm{O}_{4}=\mathrm{C}_{3}-\mathrm{C}_{6}-\mathrm{N}_{8}, \mathrm{O}_{2}=\mathrm{C}_{1}-\mathrm{C}_{5}-\mathrm{N}_{7}, \mathrm{O}_{2}=\mathrm{C}_{1}-\mathrm{C}_{3}=\mathrm{O}_{4}\right)$.

straints. This is also in agreement with the almost perfect match found between the calculated value for the most flexible molecular coordinate (the intercarbonyl dihedral angle) in the isolated $\alpha$-pyridil molecule $\left(82.3^{\circ}\right)$ and that observed in the crystalline state $\left(82^{\circ}[27]\right)$.

A few remarks can be made by comparing the values of the geometrical parameters obtained theoretically for the different conformers of $\alpha$-pyridil. In addition, some insights regarding the prevalent intramolecular interactions in the different conformers can also be obtained by comparing the geometries of $\alpha$-pyridil and some analogous compounds, like diacetyl [1], benzil [2] and $\alpha$-furil [4]:

(a) The intercarbonyl dihedral angle in the three conformers decreases in the order CCS $\boldsymbol{k}>\mathbf{T C G}>\boldsymbol{T T G}$. This is essentially a consequence of three factors: $(i)$ steric repulsion between the lone-electron pairs of the carbonyl oxygen atoms, (ii) steric repulsion between the pyridyl rings, which correlate with the number of hydrogen atoms in the ortho position located in the inner side of the molecule (2, 1 and 0 , respectively in CCSk, TCG and TTG) and (iii) the $\mathrm{CH}$... O interactions stabilizing the $\mathrm{H}-\mathrm{C}=\mathrm{C}-\mathrm{C}-\mathrm{C}=\mathrm{O}$ six-membered rings, which tend to be favored by a more planar arrangement of the molecule-there are two of such interactions in conformer CCSk, only one in TCG and none in TTG [the similar interaction stabilizing the $\mathrm{H}-\mathrm{C}=\mathrm{C}-\mathrm{C}=\mathrm{O}$ five-membered rings present in conformers TCG (one five-membered ring) and TTG (two five-membered rings) involves only atoms from the same half of the molecule and are not important in determining the geometry around the intercarbonyl bond; they are, however, important in determining the trend to the planarity exhibited by the $\mathrm{C}_{5} \mathrm{H}_{4} \mathrm{~N}-\mathrm{C}(=\mathrm{O})$ fragments]. Factor ( $i$ ) dominates in the TTG conformer, while factor (ii) and specially (iii) dominate in forms TCG and CCSk.

(b) In agreement with (a), a comparison of the value of the intercarbonyl dihedral angle calculated at DFT(B3LYP)/6-311 ++ G(d,p) level for $\alpha$-pyridil $\left(\mathrm{O}=\mathrm{C}-\mathrm{C}=\mathrm{O}\right.$ : 82.3 $3^{\circ}$ TTG; $118.3^{\circ}$ CCSk) with those found in other $\alpha$-dicarbonyl molecules previously studied in our laboratory, such as diacetyl $\left(\mathrm{CH}_{3}-\mathrm{C}(=\mathrm{O})-\mathrm{C}(=\mathrm{O})-\mathrm{CH}_{3}, \quad \mathrm{O}=\mathrm{C}-\mathrm{C}=\mathrm{O}: \quad 180^{\circ} \quad[1]\right)$, benzil $\left(\mathrm{C}_{6} \mathrm{H}_{6}-\mathrm{C}(=\mathrm{O})-\mathrm{C}(=\mathrm{O})-\mathrm{C}_{6} \mathrm{H}_{6}, \quad \mathrm{O}=\mathrm{C}-\mathrm{C}=0: 116.6^{\circ}\right.$ [2]) and $\alpha-$ furil $\left(\mathrm{C}_{4} \mathrm{OH}_{3}-\mathrm{C}(=\mathrm{O})-\mathrm{C}(=\mathrm{O})-\mathrm{C}_{4} \mathrm{OH}_{3}, \quad \mathrm{O}=\mathrm{C}-\mathrm{C}=\mathrm{O}: 6^{\circ} \quad\right.$ TTG; $\left.153^{\circ} \operatorname{CCSk}[4]\right)^{1}$ shows that the value of the intercarbonyl dihedral angle depends strongly of the structure of the substituent connected to the carbonyl groups. In acetyl, the substituents are small and the prevalent interaction is the repulsion between the lone electron pairs of the oxygen atoms, leading to a most stable trans configuration around the central bond [1]. The interactions described in (a) are similar in benzil and in the CCSk conformer of $\alpha$-pyridil, and the intercarbonyl dihedral angle is similar in these two molecules. On the other hand, when compared to the analogous conformers of $\alpha$-furil, the $\alpha$ pyridil conformers have smaller intercarbonyl dihedral angles. Both in the case of CCSk and TTG conformers, this result is in consonance with the calculated more negative charges on the carbonyl oxygen atoms in $\alpha$-furil $(-0.234$ and $-0.224 e$, for TTG and CCSk forms, respectively) than in $\alpha$-pyridyl $(-0.190$ and $-0.166 e$ ), which make more important the above mentioned factors in $\alpha$-furil (factor (i) and (iii) in the TTG and CCSk forms, respectively).

(c) The length of the $\mathrm{C}-\mathrm{C}$ intercarbonyl bond in $\alpha$-pyridil conformers varies in the range $154.7-154.4 \mathrm{pm}$. This range of values is typical for a non-conjugated $\mathrm{C}-\mathrm{C}$ single bond and follows the trend previously observed for other $\alpha$-dicarbonyls, like diacetyl, benzil, 1-phenyl-1,2-propanedione and $\alpha$-furil (155.7, 154.4, 155.0 and ca. $154.7 \mathrm{pm}$, respectively) [1-4]. As discussed in detail elsewhere [4], the long intercarbonyl bond length in $\alpha$-dicarbonyls results essentially from the balance between the relatively weak $\pi$-electron delocalization within the $\mathrm{O}=\mathrm{C}-\mathrm{C}=\mathrm{O}$ fragment and the more important $\sigma$-electron system repulsion due to the interaction between the positively charged carbonyl carbon atoms. This result is in consonance with the well-known large conformational flexibility around the $\mathrm{C}-\mathrm{C}$ central bond in $\alpha$-dicarbonyls [1-4] and also with the previously reported photochemistry of this type of compounds, where the intercarbonyl bond cleavage appears as a prevalent pathway $[3,47]$.

(d) The $\mathrm{C}_{1}-\mathrm{C}_{5}$ and $\mathrm{C}_{3}-\mathrm{C}_{6}$ bonds, connecting the $\mathrm{O}=\mathrm{C}-\mathrm{C}=\mathrm{O}$ group to the pyridyl rings $(149.5-150.7 \mathrm{pm})$ are longer than in the previous $\alpha$-dicarbonyl compounds studied in our laboratory, in particular, benzil, 1-phenyl-1,2-propanedione and $\alpha$-furil (148.7, 148.6 and $145.6-145.8 \mathrm{pm}$, respectively [2-4]). This

\footnotetext{
${ }^{1}$ In [4] the $\alpha$-furil conformers here mentioned, TTG and CCSk, were designated as III and I, respectively.
} 
result indicates that the conjugation between the pyridyl substituents and the dicarbonyl moiety is less important in $\alpha$-pyridil than between this group and the phenyl or furanyl substituents in the remaining molecules.

(e) In agreement with the reduced delocalization between the pyridyl rings and the dicarbonyl group indicated by the calculated lengths of the $C_{1}-C_{5}$ and $C_{3}-C_{6}$ bonds, the carbon-carbon and carbon-nitrogen bond lengths within the pyridyl rings were estimated to be similar to those found in benzene $(139.7 \mathrm{pm}$ [48]) and pyridine (139.3 and $133.8 \mathrm{pm}$, average value for CC and $\mathrm{CN}$ bond lengths, respectively [49]) in all conformers of $\alpha$ pyridil: the carbon-carbon bond lengths vary within the range 138.9-139.9 pm, and the nitrogen-carbon bond lengths within the range $132.8-134.2 \mathrm{pm}$.

(f) The $\mathrm{O}_{2}=\mathrm{C}_{1}-\mathrm{C}_{3}$ and $\mathrm{C}_{1}-\mathrm{C}_{3}=\mathrm{O}_{4}$ angles in $\alpha$-pyridil correspond to the valence angles that differ more among the various conformers. As expected, in the most stable TTG conformer, where the steric repulsion between the lone-electron pairs of the carbonyl oxygen atoms dominates, the sum of these angles attain its maximum value $\left(238.6^{\circ}\right)$, while in the TCG and CCSk conformers it is $235.9^{\circ}$ and $235.6^{\circ}$, respectively.

An important result coming out from the calculations in relation with the experimental study described in this work concerns the relatively high energies predicted for the two less stable conformers of $\alpha$-pyridil. In fact, using the Boltzmann distribution and the calculated relative energies of the conformers, the estimated joint population of these two forms in the gaseous phase in the range of temperatures used to sublimate the compound $\left(80-125^{\circ} \mathrm{C}\right)$ is less than $0.2 \%$. In practical terms, this result shows the impossibility of trapping the higher energy forms of $\alpha$-pyridil in the cryogenic matrices in a detectable amount. Indeed, as described in detail below, only the most stable conformer could be observed experimentally in the present investigation.

\subsection{Infrared spectroscopy: analysis of the matrix isolation spectra and UV-irradiation experiments}

The $\alpha$-pyridil molecule has 66 fundamental vibrations (of $34 \mathrm{~A}$ and $32 B$ symmetry, for the $C_{2}$ conformers), all of them active in the infrared. The definition of the internal coordinates adopted in the vibrational analysis undertaken in this study is provided in Table S2 (Supplementary Material). The calculated frequencies, infrared intensities and potential energy distributions resulting from normal mode analysis, carried out for the experimentally relevant TTG conformer, are presented in Table S3 (Supplementary Material). The infrared spectra of $\alpha$-pyridil isolated in both solid argon and xenon (as-deposited matrices; sublimation and CsI substrate temperatures: $\mathrm{Ar}, 85^{\circ} \mathrm{C}$ and $10 \mathrm{~K}$; $\mathrm{Xe}, 125^{\circ} \mathrm{C}$ and $20 \mathrm{~K}$ ) together with the calculated spectrum of the TTG conformer are presented in Fig. 2. Table 1 presents the assignments for the fundamental bands, which were strongly aided by the good agreement between the experimental and the calculated data.

According to the calculations, the 4 most intense bands in the spectrum of $\alpha$-pyridil correspond to the stretching vibrations of the $C=0$ groups (observed in argon at $c a .1727$ and $1702 \mathrm{~cm}^{-1}$ ), the asymmetric stretching of the $\mathrm{C}-\mathrm{C}$ bonds connecting the carbonyl groups to the pyridyl rings $\left(\nu \mathrm{C}-\mathrm{C}_{\alpha}\right.$ as; $\left.1227 \mathrm{~cm}^{-1}\right)$ and a skeletal deformational mode observed at $c a .654 \mathrm{~cm}^{-1}$, which has a significant contribution from the in-plane asymmetric bending mode of the carbonyl groups. All these bands show extensive matrix-site splitting as it could be expected considering the high flexibility of the molecule around the intercarbonyl $\mathrm{C}-\mathrm{C}$ bond (the calculated frequency for the intercarbonyl $\mathrm{C}-\mathrm{C}$ torsion is as low as $24 \mathrm{~cm}^{-1}$;
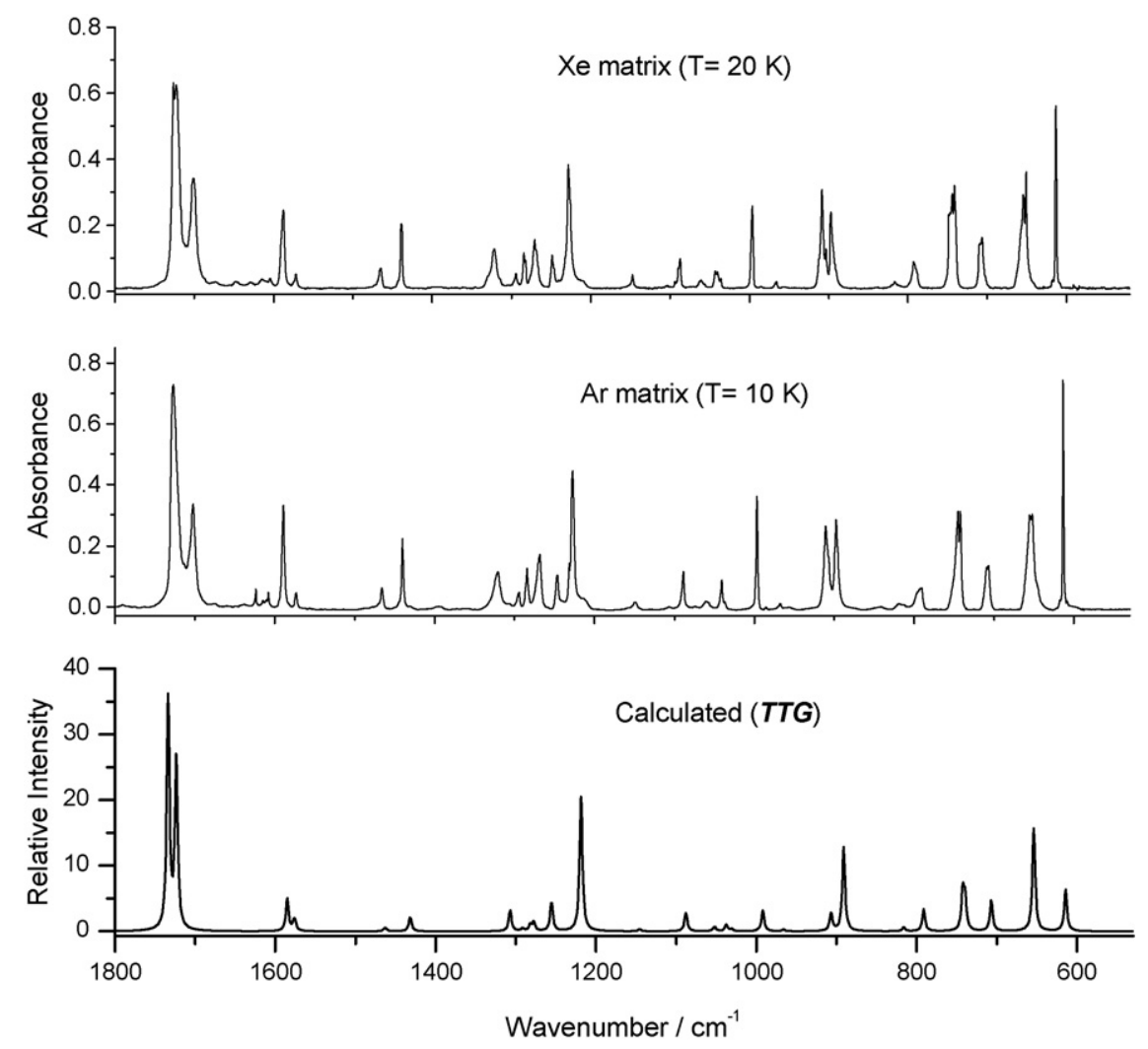

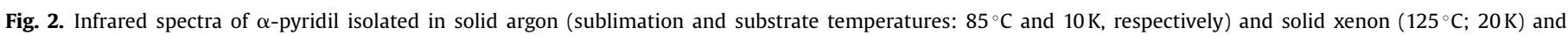
DFT(B3LYP)/6-311++G(d,p) calculated spectrum for the $\boldsymbol{T T G}$ conformer. 
Table 1

Experimental (matrix-isolation) and calculated (TTG form) vibrational data for $\alpha$-pyridil and vibrational assignments based on the results of normal coordinate analysis ${ }^{\mathrm{a}}$

\begin{tabular}{|c|c|c|c|c|c|c|c|}
\hline \multirow[t]{2}{*}{ Approximate description } & & \multicolumn{2}{|c|}{ Calculated } & \multicolumn{4}{|l|}{ Experimental } \\
\hline & & $v$ & $I$ & $\operatorname{Ar}(10 \mathrm{~K})$ & $I^{\mathrm{b}}$ & $\mathrm{Xe}(20 \mathrm{~K})$ & $I^{\mathrm{b}}$ \\
\hline$v(\mathrm{C}-\mathrm{H} 2) \mathrm{s}$ & $A$ & 3134.9 & 0.9 & 3147.5 & w & 3145.5 & w \\
\hline$v(\mathrm{C}-\mathrm{H} 2)$ as & $B$ & 3134.8 & 6.4 & 3147.5 & w & 3145.5 & w \\
\hline$\nu(\mathrm{C}-\mathrm{H} 3)$ as & $A$ & 3123.2 & 8.5 & $3073.7 / 3070.4$ & w & 3070.0 & w \\
\hline$\nu(\mathrm{C}-\mathrm{H} 3)$ as & $B$ & 3123.1 & 16.0 & $3073.7 / 3069.5$ & w & 3070.0 & w \\
\hline$v(\mathrm{C}-\mathrm{H} 4)$ as & $B$ & 3106.0 & 12.6 & $3064.6 / 3060.4$ & w & $3058.4 / 3053.7$ & w \\
\hline$v(\mathrm{C}-\mathrm{H} 4) \mathrm{s}$ & $A$ & 3106.0 & 2.4 & $3064.6 / 3060.4$ & w & $3051.8 / 3050.6$ & w \\
\hline$v(\mathrm{C}-\mathrm{H} 1) \mathrm{s}$ & $A$ & 3087.1 & 11.3 & 3017.2 & w & $3015.5 / 3009.7$ & w \\
\hline$\nu(\mathrm{C}-\mathrm{H} 1)$ as & $B$ & 3087.0 & 14.6 & 3017.2 & w & $3015.5 / 3009.7$ & w \\
\hline$\nu(C=O) s$ & $A$ & 1733.8 & 225.8 & $1728.2 / 1726.8 / 1713.4$ & $\mathrm{~S} / \mathrm{S} / \mathrm{sh}$ & 1727.7/1726.4/1723.0/1721.6/1712.4/1709.6 & $\mathrm{sh} / \mathrm{S} / \mathrm{S} / \mathrm{sh}$ \\
\hline$\nu(\mathrm{C}=0)$ as & $B$ & 1723.5 & 169.5 & $1703.6 / 1702.2$ & $\operatorname{sh} / \mathrm{S}$ & $1702.5 / 1701.2$ & $\operatorname{sh} / \mathrm{S}$ \\
\hline$\nu$ (ring 3$)$ as & $B$ & 1585.2 & 9.2 & $1594.7 / 1589.5$ & $\mathrm{sh} / \mathrm{m}$ & $1591.0 / 1589.2 / 1587.7$ & $\operatorname{sh} / \operatorname{sh} / \mathrm{S}$ \\
\hline$\nu($ ring 3$) \mathrm{s}$ & $A$ & 1585.2 & 22.3 & $1594.7 / 1589.5$ & $\mathrm{sh} / \mathrm{m}$ & $1591.1 / 1587.8$ & sh \\
\hline$\nu($ ring 4$) \mathrm{s}$ & $A$ & 1577.1 & 5.3 & 1573.4 & w & $1591.1 / 1574.7$ & $\mathrm{sh}$ \\
\hline$v($ ring 4$)$ as & $B$ & 1575.6 & 7.1 & 1573.4 & w & 1571.9 & w \\
\hline$\nu($ ring 6$) \mathrm{s} ; \delta(\mathrm{C}-\mathrm{H} 4) \mathrm{s}$ & $A$ & 1463.6 & 2.0 & 1467.7 & sh & 1466.3 & sh \\
\hline$\delta(\mathrm{C}-\mathrm{H} 4)$ as; $v$ (ring 6$)$ as & $B$ & 1462.6 & 1.6 & 1466.1 & w & $1465.4 / 1464.5$ & $\mathrm{w} / \mathrm{w}$ \\
\hline$\delta(\mathrm{C}-\mathrm{H} 3) \mathrm{s}$ & $A$ & 1434.3 & 0.7 & 1444.7 & $\operatorname{sh}$ & $1443.2 / 1444.7$ & $\mathrm{sh} / \mathrm{sh}$ \\
\hline$\delta(\mathrm{C}-\mathrm{H} 3)$ as & $B$ & 1431.7 & 13.2 & $1440.5 / 1431.4$ & $\mathrm{~S} / \mathrm{sh}$ & 1439.1 & $\mathrm{~m}$ \\
\hline$\nu($ ring 5$) \mathrm{s}$ & $A$ & 1307.1 & 19.7 & $1321.3 / 1317.2$ & $\mathrm{~m} / \mathrm{sh}$ & $1330.1 / 1323.3 / 1322.0 / 1314.6$ & $\mathrm{sh} / \mathrm{sh} / \mathrm{m} / \mathrm{sh}$ \\
\hline$\nu($ ring 5$)$ as & $B$ & 1291.6 & 2.4 & 1294.4 & w & 1294.5 & w \\
\hline$\delta(\mathrm{C}-\mathrm{H} 4) \mathrm{s}$ & $A$ & 1282.1 & 6.1 & $1284.3 / 1282.6$ & $\mathrm{~m} / \mathrm{sh}$ & $1284.5 / 1282.3$ & $\mathrm{~m} / \mathrm{m}$ \\
\hline$\nu($ ring 2$)$ as & $B$ & 1277.8 & 8.7 & $1273.2 / 1268.3$ & $\mathrm{sh} / \mathrm{m}$ & $1270.8 / 1269.2$ & $\mathrm{~m} / \mathrm{sh}$ \\
\hline$\nu($ ring 2$) \mathrm{s} ; \nu($ ring 5$) \mathrm{s} ; \nu\left(\mathrm{C}-\mathrm{C}_{\alpha}\right) \mathrm{s}$ & $A$ & 1255.5 & 28.4 & 1246.3 & $\mathrm{~m}$ & $1248.9 / 1246.4 / 1240.4$ & $\mathrm{~m} / \mathrm{sh} / \mathrm{w}$ \\
\hline$\nu\left(\mathrm{C}-\mathrm{C}_{\alpha}\right)$ as & $B$ & 1218.7 & 131.2 & $1231.7 / 1227.4 / 1213.5$ & $\mathrm{w} / \mathrm{S} / \mathrm{w}$ & $1232.7 / 1228.5 / 1210.2$ & $\operatorname{sh} / \mathrm{S} / \mathrm{sh}$ \\
\hline$\delta(\mathrm{C}-\mathrm{H} 2) \mathrm{s}$ & $A$ & 1145.7 & 1.0 & 1149.5 & w & 1147.4 & w \\
\hline$\delta(\mathrm{C}-\mathrm{H} 2)$ as & $B$ & 1145.2 & 0.9 & 1149.5 & w & 1147.4 & w \\
\hline$\nu($ ring 2$) \mathrm{s} ; \delta(\mathrm{C}-\mathrm{H} 3) \mathrm{s} ; \delta(\mathrm{C}-\mathrm{H} 1) \mathrm{s}$ & $A$ & 1088.6 & 1.3 & 1088.8 & $\mathrm{~m}$ & $1094.2 / 1089.5 / 1087.3$ & $\mathrm{sh} / \mathrm{sh} / \mathrm{m}$ \\
\hline$\nu($ ring 2$)$ as; $\delta(\mathrm{C}-\mathrm{H} 3)$ as; $\delta(\mathrm{C}-\mathrm{H} 1)$ as & $B$ & 1087.8 & 16.3 & 1088.8 & $\mathrm{~m}$ & $1094.2 / 1089.5 / 1087.3$ & $\mathrm{sh} / \mathrm{sh} / \mathrm{m}$ \\
\hline$v($ ring 6$) s ; v(C-C)$ & $A$ & 1052.3 & 4.4 & 1060.3 & w & $1063.3 / 1061.1$ & $\mathrm{w}$ \\
\hline$v($ ring 6$)$ as & $B$ & 1037.6 & 6.3 & 1040.8 & w & $1043.2 / 1040.2$ & $\mathrm{w} / \mathrm{w}$ \\
\hline$\nu($ ring 6$) \mathrm{s}, \nu($ ring 1$) \mathrm{s}$ & $A$ & 1030.8 & 2.0 & 1037.1 & w & 1036.0 & w \\
\hline$\gamma(\mathrm{C}-\mathrm{H} 3)$ as & $B$ & 996.6 & 0.1 & 996.8 & S & 998.0 & sh \\
\hline$\gamma(\mathrm{C}-\mathrm{H} 3) \mathrm{s}$ & $A$ & 996.1 & $<0.1$ & 996.8 & $\mathrm{~S}$ & 998.0 & $\mathrm{sh}$ \\
\hline$\nu($ ring 1$) \mathrm{s} ; \delta($ ring 2$) \mathrm{s}$ & $A$ & 992.2 & 0.1 & $996.8 / 985.5$ & $\mathrm{~S} / \mathrm{w}$ & $996.3 / 985.4$ & $\mathrm{~S} / \mathrm{w}$ \\
\hline$\delta($ ring 2$)$ as; $\nu$ (ring 1$)$ as & $B$ & 991.9 & 19.9 & $996.8 / 985.5$ & $\mathrm{~S} / \mathrm{w}$ & $996.3 / 985.4$ & $\mathrm{~S} / \mathrm{w}$ \\
\hline$\gamma(\mathrm{C}-\mathrm{H} 4)$ as & $B$ & 966.1 & 1.2 & $970.0 / 967.8 / 955.3$ & $\mathrm{sh} / \mathrm{w} / \mathrm{w}$ & $968.3 / 967.4 / 965.7 / 957.2$ & $\mathrm{sh} / \mathrm{w} / \mathrm{w} / \mathrm{w}$ \\
\hline$\gamma(\mathrm{C}-\mathrm{H} 4) \mathrm{s}$ & $A$ & 965.8 & 0.2 & $970.0 / 967.8 / 955.3$ & $\mathrm{sh} / \mathrm{w} / \mathrm{w}$ & $968.3 / 967.4 / 965.7 / 957.2$ & $\mathrm{sh} / \mathrm{w} / \mathrm{w} / \mathrm{w}$ \\
\hline$\gamma(\mathrm{C}-\mathrm{H} 2)$ as & $B$ & 906.8 & 16.5 & 910.7 & $\mathrm{~m}$ & $912.0 / 908.6$ & $\mathrm{sh} / \mathrm{m}$ \\
\hline$\gamma(\mathrm{C}-\mathrm{H} 2) \mathrm{s}$ & $A$ & 904.8 & 0.2 & 907.5 & $\mathrm{sh}$ & 903.3 & w \\
\hline Skeletal & $B$ & 891.0 & 80.3 & $897.8 / 895.6$ & $\mathrm{~m} / \mathrm{sh}$ & $897.0 / 894.6 / 890.5$ & $\mathrm{~m} / \mathrm{sh} / \mathrm{sh}$ \\
\hline$\tau($ ring 1$) s ; \gamma(C=0) s$ & $A$ & 816.2 & 3.5 & $819.7 / 812.7$ & $w / w$ & 816.7 & $\mathrm{w}$ \\
\hline$\tau($ ring 1$)$ as; $\gamma(C=0)$ as & $B$ & 791.2 & 21.3 & 790.6 & w & 792.9/791.5/789.3/788.1 & $\mathrm{w} / \mathrm{sh} / \mathrm{sh} / \mathrm{sh}$ \\
\hline$\gamma \gamma(\mathrm{C}-\mathrm{H} 1) \mathrm{s}$ & $A$ & 742.5 & 36.9 & 746.8 & $\mathrm{sh}$ & $748.4 / 747.0 / 744.3$ & $\mathrm{~m} / \mathrm{m} / \mathrm{m}$ \\
\hline$\gamma(\mathrm{C}-\mathrm{H} 1)$ as; $\tau($ ring 3$)$ as & $B$ & 739.6 & 28.8 & $745.2 / 742.2$ & $\mathrm{~m} / \mathrm{m}$ & 741.4 & $\mathrm{~m}$ \\
\hline$\delta($ ring 1$) \mathrm{s}$ & $A$ & 732.4 & 0.4 & $745.2 / 742.2$ & $\mathrm{~m} / \mathrm{m}$ & 740.2 & sh \\
\hline$\delta($ ring 1$)$ as & $B$ & 707.2 & 11.7 & 709.5 & $\mathrm{~m}$ & $710.2 / 708.5$ & $\mathrm{~m} / \mathrm{m}$ \\
\hline$\tau($ ring 3$) s ; \gamma(C=0) s$ & $A$ & 706.7 & 18.2 & 707.0 & $\mathrm{~m}$ & 706.5 & $\mathrm{~m}$ \\
\hline Skeletal & $B$ & 653.9 & 98.6 & 655.9/654.3/652.1/645.6 & $\mathrm{m} / \mathrm{m} / \mathrm{m} / \mathrm{sh}$ & 657.1/654.7/650.9/646.6 & $\mathrm{sh} / \mathrm{m} / \mathrm{m} / \mathrm{sh}$ \\
\hline$\delta($ ring 3$) s$ & $A$ & 617.9 & 0.2 & 613.5 & $\mathrm{~S}$ & $613.7 / 613.1 / 612.1$ & $\mathrm{~S} / \mathrm{sh} / \mathrm{sh}$ \\
\hline$\delta($ ring 3 ) as & $B$ & 614.2 & 39.9 & 613.5 & $\mathrm{~S}$ & 613.7/613.1/612.1 & $\mathrm{S} / \mathrm{sh} / \mathrm{sh}$ \\
\hline Skeletal & $A$ & 474.8 & 4.4 & 479.7 & w & $483.4 / 478.0$ & $\mathrm{w} / \mathrm{w}$ \\
\hline$\tau($ ring 4$)$ as & $B$ & 472.0 & 11.3 & $476.3 / 469.6$ & $\mathrm{w} / \mathrm{sh}$ & 473.6 & w \\
\hline$\tau($ ring 2$) s ; \tau($ ring 4$) s$ & $A$ & 422.5 & 1.9 & 424.2 & $\mathrm{sh}$ & 423.9 & w \\
\hline$\tau($ ring 2$)$ as & $B$ & 422.1 & 9.2 & $422.2 / 420.5 / 417.8$ & $\mathrm{w} / \mathrm{sh} / \mathrm{w}$ & 422.4/421.4/419.6 & $\mathrm{sh} / \mathrm{w} / \mathrm{w}$ \\
\hline$\tau($ ring 4$) s ; \tau($ ring 2$) s$ & $A$ & 399.4 & 1.5 & n.i. & & n.i & \\
\hline$\tau($ ring 4$)$ as; $\tau$ (ring 2$)$ as & $B$ & 395.4 & 0.9 & n.i. & & n.i. & \\
\hline$\delta(C=0) s$ & $A$ & 325.9 & 4.7 & n.i. & & n.i. & \\
\hline$\delta(\mathrm{C}=0)$ as; $\mathrm{w}($ ring $)$ as & $B$ & 263.8 & 27.4 & n.i. & & n.i. & \\
\hline $\mathrm{w}($ ring $) \mathrm{s}$ & $A$ & 258.6 & 3.2 & n.i. & & n.i. & \\
\hline$\tau($ ring 1$) \mathrm{s}$ & $A$ & 148.5 & 0.1 & n.i. & & n.i. & \\
\hline$\tau($ ring 1$)$ as & $B$ & 145.8 & 1.7 & n.i. & & n.i. & \\
\hline$\delta\left(\mathrm{CCC}_{\alpha}\right)$ as & $B$ & 120.8 & 0.0 & n.i & & n.i & \\
\hline$\delta\left(\mathrm{CCC}_{\alpha}\right) \mathrm{s}$ & $A$ & 111.3 & 0.1 & n.i & & n.i & \\
\hline$\tau\left(C-C_{\alpha}\right) s$ & $A$ & 52.4 & 0.4 & n.i & & n.i & \\
\hline$\tau\left(\mathrm{C}-\mathrm{C}_{\alpha}\right)$ as & $B$ & 41.6 & 4.1 & n.i & & n.i & \\
\hline$\tau(C-C)$ & $A$ & 24.0 & 3.5 & n.i & & n.i & \\
\hline
\end{tabular}

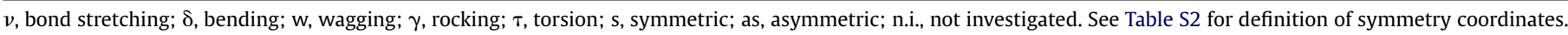
Only bands assigned to fundamental modes are presented in the Table.

a Frequencies $\left(\mathrm{cm}^{-1}\right.$, scaled by 0.978$)$, calculated intensities in $\mathrm{km} \mathrm{mol}^{-1}$.

b Experimental intensities are presented in qualitative terms: $\mathrm{S}=$ strong, $\mathrm{m}=$ medium, $\mathrm{w}=$ weak, $\mathrm{sh}=$ shoulder. 
see Table 1 ), and were fairly well predicted by the calculations both regarding frequencies and relative intensities (see Table 1 and Fig. 2). The general agreement between the calculated and experimental data for the less intense bands is also good, as shown in Fig. 2, so that the proposed assignments (Table 1) could be made with high degree of confidence.

UV irradiation $(\lambda>235 \mathrm{~nm})$ of matrix-isolated $\alpha$-pyridil resulted in an intensity decrease of the bands of the initial spectrum and appearance of new bands due to photoproducts. In xenon matrix, the intensity of the bands due to the reactant decreases only by ca. $20 \%$ after $5 \mathrm{~h}$ irradiation, indicating that the observed photoprocesses have a relatively low efficiency. In argon matrix, similar results were obtained, but the process is even less efficient, which points to a photochemical mechanism involving an $n \rightarrow \pi^{*}$ excitation and a triplet state.

In order to identify the chemical species formed by irradiation of the matrix, a series of theoretical calculations of the spectroscopic signatures of possible photoproducts was carried out. The following putative general types of photoprocesses could $a$ priori be considered: $(i)$ intercarbonyl bond cleavage, leading to formation<smiles>CC(=O)c1ccccn1</smiles><smiles>O=C(C(=O)c1ccccn1)c1ccccn1</smiles><smiles>[3H][3H]</smiles><smiles>O=[C]c1ccccn1</smiles><smiles>O=Cc1ccccn1</smiles><smiles>C1CCCCC1</smiles><smiles>c1ccc(-c2ccccn2)nc1</smiles><smiles>CN</smiles>

B

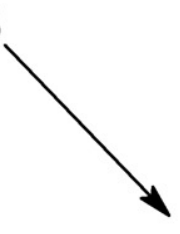<smiles>O=C(Cl)C(=O)C(=O)c1ccccn1</smiles><smiles>[14CH3]NC(=O)C(=O)c1ccccn1</smiles><smiles>C1=CCC=C1</smiles><smiles>[R]C(=O)C(C)=O</smiles><smiles>[R][R]C(=O)C([R2])C([R2])C([R])=O</smiles><smiles>[R][R]=C=[W]C=CC1=CC=C1</smiles>

Hück =

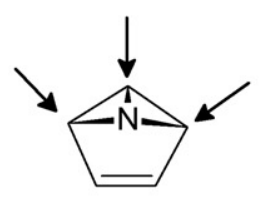<smiles>CC(C)N1C2CCCC1C2(C)C</smiles>

Dew $=$<smiles>CC1CN(C)CCN1C</smiles><smiles>CC1C(C)C2C=CC1C2(C)C</smiles>

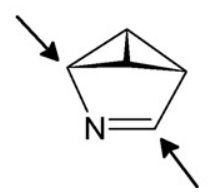

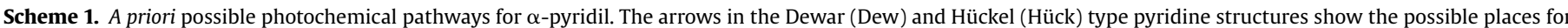
the bonding of these groups to the dicarbonyl moiety in $\alpha$-pyridil. Pathways A and B were not observed experimentally. 
of 2-pyridylcarbonyl radicals, that can then loose carbon monoxide followed by recombination to form either di-(2-pyridyl) ketone or 2,2'-bipyridine (pathway A in Scheme 1); (ii) isomerization of the pyridine rings to the valence Dewar or Hückel (aza-benzvalene) isomers (B and C in Scheme 1).

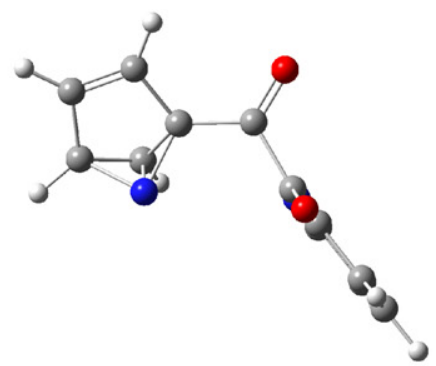

$1 \mathrm{~A}(41.8)$

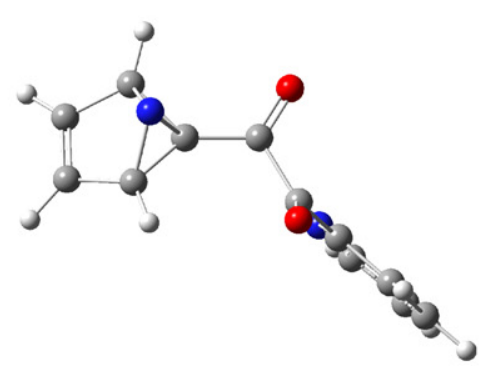

$1 \mathrm{C}(36.8)$

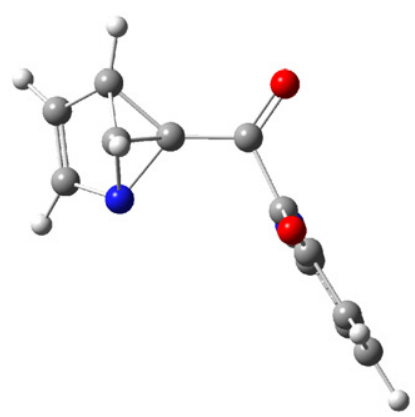

2B (86.2)

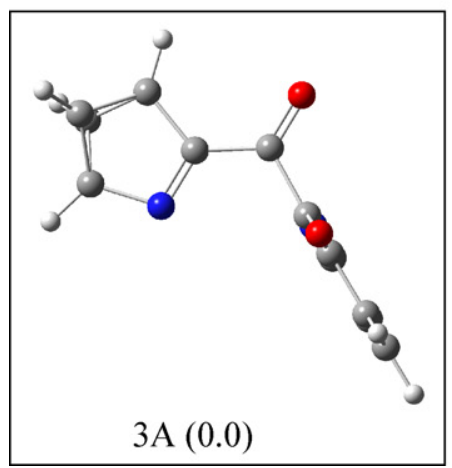

The first type of reaction was observed for 1-phenyl-1,2propandione isolated in cryogenic inert matrices [3], leading to single decarbonylation and production of acetophenone. In turn, efficient isomerization of Kekule ring structures to their Dewar analogues have been found to take place in matrices for related

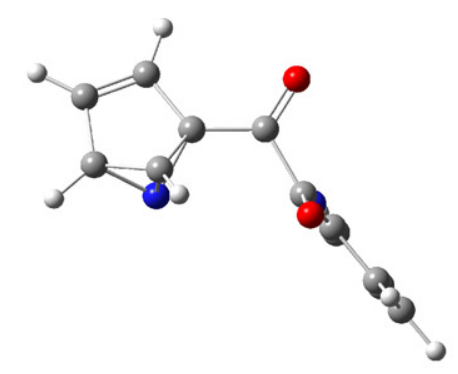

1B (36.2)

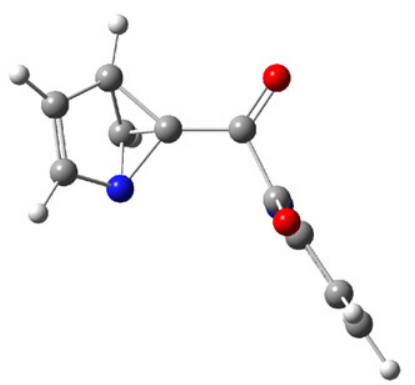

$2 \mathrm{~A}(85.4)$
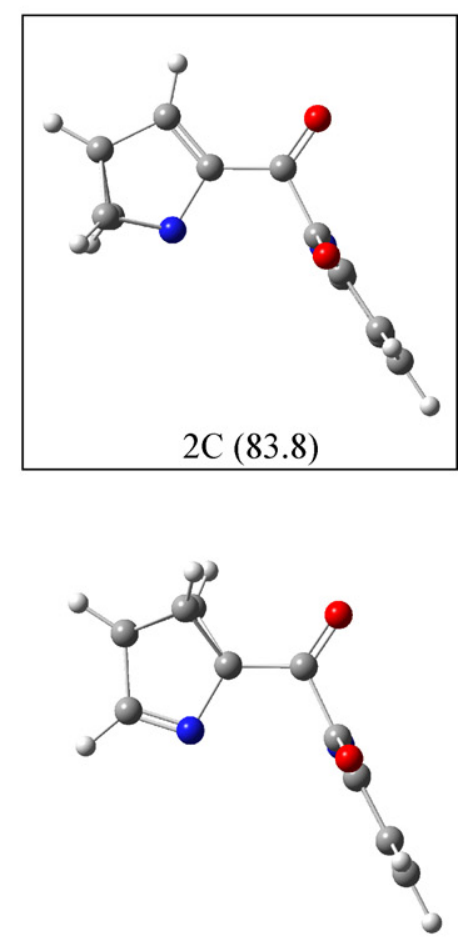

$3 \mathrm{~B}(6.0)$

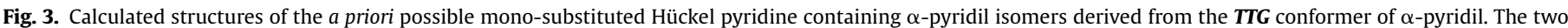

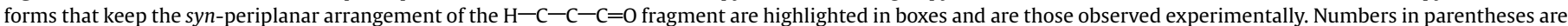

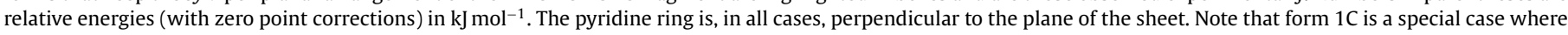

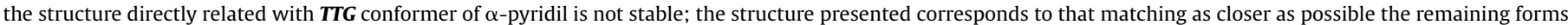
shown in the figure. 
compounds, like $\alpha$-pyrones and $\alpha$-thiopyranones [50-53], while some Dewar pyridines, including the unsubstituted one, could also be observed experimentally as result of photochemical transformation of their most stable Kekule isomers [54-62]. On the other hand, to the best of our knowledge, experimental observation of Hückel pyridine isomers was only reported once, in a study where the ultrafast dynamics of isomerization of pyridine (and a few other analogue compounds) was investigated by femtosecond-resolved mass spectrometry complemented by DFT/ab initio calculations [62]. Nevertheless, some Hückel isomers of pyridine have been consistently predicted by different theoretical methods to be most stable than the Dewar forms [62-65], so that the possibility of their photochemical formation under the present experimental conditions could not be excluded. Moreover, according to Zong et al. [62], conical intersections appear to be fundamental in driving the valence photoisomerization reactions of pyridine, which then take place partially in the ground-state potential energy surface. This fact enabled us to exclude a priori other valence isomerization reactions within the pyridine rings (e.g. to the prismane and bicyclopropyl-2,2'-diene like species), since the energies required for these processes to take place are too high to make them possible under the present experimental conditions (the maximum energy available in our experiment is $c a .500 \mathrm{~kJ} \mathrm{~mol}^{-1}$ and those required for those isomerization processes are over $630 \mathrm{~kJ} \mathrm{~mol}^{-1}$ [62]).

In the specific case of isomerization of the pyridyl groups of $\alpha$ pyridil to their Dewar forms, subsequent photochemical processes could be expected to take place, in a similar way as previously observed for $\alpha$-pyrones and $\alpha$-thiopyranones [50-53], resulting in the production of cyclobutadiene (or aza-cyclobutadiene, or a mixture of these compounds, depending on the specific pyridine Dewar isomer initially formed) and cyano-or ethyne-substituted ethanediones (see Scheme 1). In turn, if they were formed, these ethanediones could also undergo single or double decarbonylation to form the corresponding ketones or dicyano (or diethyne, or cyano-ethyne) derivatives. Other a priori possible secondary photochemical reactions starting from Dewar pyridines would be the release of HCN or ethyne and formation of cyclobutadien-or azacyclobutadien-ethanediones (see Scheme 1), in consonance with the known photochemistry of Dewar pyridine [62]. However, the spectroscopic results doubtlessly show that the photochemistry of matrix isolated $\alpha$-pyridil is considerably simpler than it could be expected. In fact, none of the characteristic bands of carbon monoxide $\left\{\right.$ at $2138(\mathrm{Ar})$ or $\left.2133(\mathrm{Xe}) \mathrm{cm}^{-1}[66,67]\right\}, \mathrm{HCN}\{3306,2098,721$ (Ar) $\mathrm{cm}^{-1} ;$ ca. 3280, 2090, $718(\mathrm{Xe}) \mathrm{cm}^{-1}$ [68]\}, ethyne $\{3303 / 3289$ (Fermi resonance doublet) and $737(\mathrm{Ar}) \mathrm{cm}^{-1}$ [69]\} and cyclobutadiene $\left\{1241,575(\mathrm{Ar}) ; 1239,574(\mathrm{Xe}) \mathrm{cm}^{-1}[51,70]\right\}$ were observed in the spectra of the photolysed matrix, implying that all putative reaction steps involving the production of these species did not take place and could be promptly discarded. This significantly reduces the number of possible photoproducts and, in particular, excludes the intercarbonyl bond cleavage reaction path and all reactions putatively occurring after formation of the pyridine valence isomers' based products.

In addition, comparison of the experimental spectra of the photolysed matrix with those of Dewar pyridine containing species also showed unambiguously that the isomerization of the pyridine rings of $\alpha$-pyridil to Dewar forms did not take place. On the other hand, the results are in consonance with the presence in the photolysed matrix of Hückel pyridine containing compounds.

It is worth mentioning that the number of possible a priori chemical species derived from $\alpha$-pyridil containing the Hückel pyridine moiety is still very large. Unsubstituted Hückel pyridine may exist in three different structures: 1-aza-benzvalene, 2-aza-benzvalene and 3-aza-benzvalene (see Scheme 1). Upon single substitution in a position vicinal to the nitrogen atom (a requirement for a deriva-
(A)
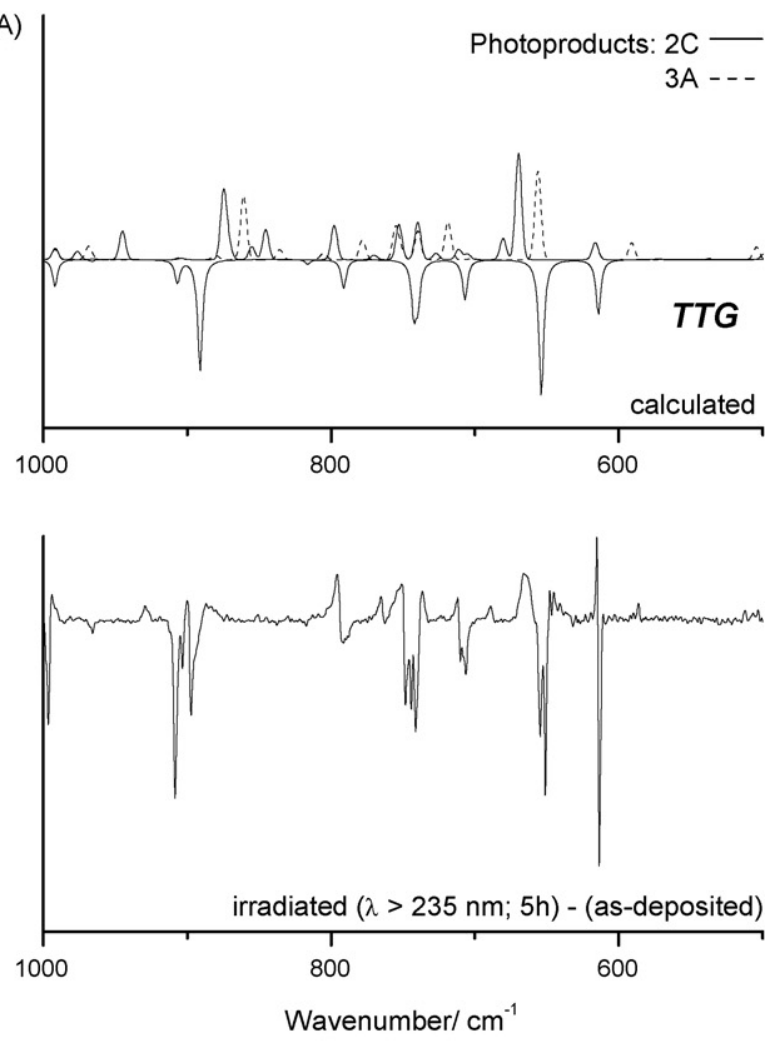

(B)
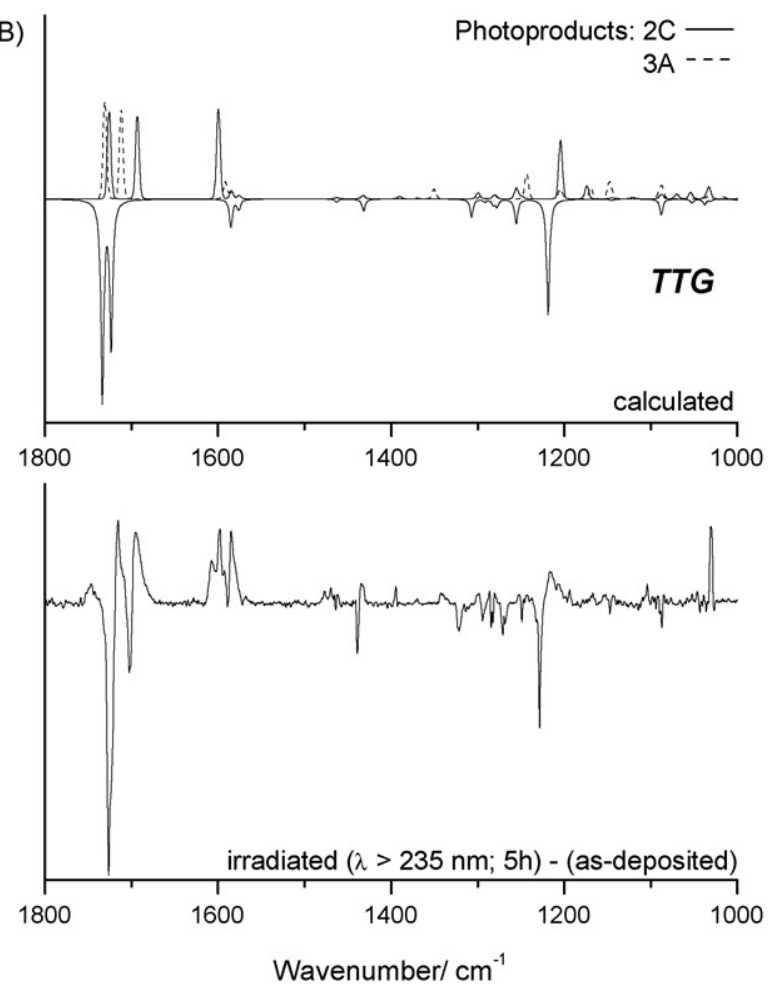

Fig. 4. (A) $1000-500 \mathrm{~cm}^{-1}$ spectral range. (B) $1800-1000 \mathrm{~cm}^{-1}$ spectral range-bottom: experimental difference spectrum for $\alpha$-pyridil isolated in xenon matrix [(irradiated sample after $5 \mathrm{~h}$ of irradiation with UV light, $\lambda>235 \mathrm{~nm}$ ) minus (as-deposited sample)]. Top: calculated spectra for the TTG conformer of $\alpha$-pyridil (bands pointing down) and for photoproducts $2 \mathrm{C}$ and $3 \mathrm{~A}$ (bands pointing up). The calculated intensities of the bands due to the photoproducts assume a 1:1 ratio of these species; those of the reactant bands were arbitrarily chosen in order to reproduce approximately the experimental difference spectrum shown in the figure. 
tive of $\alpha$-pyridil), there are three possible different isomeric forms derived from 1-and 2-aza-benzvalene and two different isomeric forms derived from 3-aza-benzvalene. Considering then that the isomerization reactions might occur in one or in both of the pyridine rings of $\alpha$-pyridil, and taking into account the conformational degrees of rotation around both the intercarbonyl bond and the two $\mathrm{C}-\mathrm{C}$ bonds linking the dicarbonyl moiety to the pyridine rings, the possible structures quickly grow up to a non-manageable number. However, though the identification of the precise Hückel-type pyridine containing species obtained in the described photolysis experiments appeared a priori an impossible task, the type of Hückel structures produced under the present experimental conditions could still be guessed. First of all, extensive molecular rearrangements in a matrix are not favoured due to the geometric constraints imposed by the matrix cage. This means that the formed Hückel pyridine containing species shall be directly related with the initially trapped $\mathbf{T T G}$ conformer of $\alpha$-pyridil. In addition, the dominant stabilizing interactions existent in this conformer shall be kept in the photoproducts, in particular, the nearly synperiplanar arrangement of the $\mathrm{H}-\mathrm{C}-\mathrm{C}-\mathrm{C}=\mathrm{O}$ fragment. Finally, we can expect that singly substituted species (i.e. species containing just one Hückel type pyridine ring) are prevalent. Under these three

Table 2

Assignment of the observed infrared bands of the photoproducts $2 \mathrm{C}$ and $3 \mathrm{~A}^{\mathrm{a}}$

\begin{tabular}{|c|c|c|c|}
\hline \multirow[t]{2}{*}{ Approximate description ${ }^{b}$} & \multirow{2}{*}{$\begin{array}{l}\text { Obs. } \\
\text { Xe matrix }\end{array}$} & \multicolumn{2}{|c|}{ Calculated } \\
\hline & & $2 \mathrm{C}$ & $3 \mathrm{~A}$ \\
\hline$\nu \mathrm{C}=\mathrm{Op}$ & 1716 & 1725 & 1731 \\
\hline$\nu \mathrm{C}=\mathrm{Oh}$ & 1695 & 1693 & 1712 \\
\hline$\nu \mathrm{C}=\mathrm{Ch}$ & $1608 / 1599$ & 1599 & \\
\hline$\nu \mathrm{C}=\mathrm{N} \mathrm{h}$ & 1592 & & 1592 \\
\hline$\nu$ ring $\mathrm{p}$ & 1584 & 1584 & 1584 \\
\hline$\delta \mathrm{C}-\mathrm{H} / v$ ring $\mathrm{p}$ & $1478 / 1470$ & 1463 & 1462 \\
\hline$\delta \mathrm{C}-\mathrm{H} \mathrm{p}$ & 1443 & 1432 & 1432 \\
\hline$\delta \mathrm{C}-\mathrm{H} \mathrm{h}$ & 1370 & & 1372 \\
\hline$v \mathrm{C}-\mathrm{C}_{\alpha} \mathrm{h}$ & 1341 & & 1350 \\
\hline$v$ ring $/ \delta C-H \mathrm{p}$ & 1299 & 1299 & \\
\hline$\delta \mathrm{C}-\mathrm{H} / v$ ring $\mathrm{p}$ & 1280 & 1280 & 1280 \\
\hline$\nu \mathrm{C}-\mathrm{C}_{\alpha} \operatorname{sym}$ & 1252 & 1255 & \\
\hline$\nu C-C_{\alpha} p$ & 1243 & & 1243 \\
\hline$\delta \mathrm{C}-\mathrm{H} \mathrm{h}$ & $1215 / 1206$ & 1204 & 1204 \\
\hline$\nu \mathrm{C}-\mathrm{Nh}$ & 1168 & 1174 & \\
\hline$v$ ring $\mathrm{h}$ & 1168 & & 1169 \\
\hline$\delta \mathrm{C}-\mathrm{Hh}$ & 1153 & & 1148 \\
\hline$\delta \mathrm{C}-\mathrm{H} \mathrm{p}$ & 1143 & & 1144 \\
\hline$v$ ring $/ \delta \mathrm{C}-\mathrm{H} \mathrm{h}$ & 1104 & 1121 & \\
\hline$\gamma \mathrm{C}-\mathrm{Hh}$ & 1077 & 1070 & \\
\hline$\nu \mathrm{C}-\mathrm{C}$ intercarbonyl & 1046 & 1053 & \\
\hline$\delta$ ring $\mathrm{p}$ & 1030 & 1035 & \\
\hline$\gamma \mathrm{C}-\mathrm{Hh}$ & 1030 & 1032 & 1032 \\
\hline$\delta$ ring $\mathrm{p}$ & 994 & 992 & \\
\hline$\delta$ ring $\mathrm{h}$ & 930 & 945 & \\
\hline$\delta$ ring $\mathrm{h}$ & 887 & 874 & \\
\hline$\gamma \mathrm{C}=\mathrm{Op}$ & 883 & & 861 \\
\hline$\gamma C=O p$ & 795 & 798 & \\
\hline$\delta$ skeletal & 765 & & 778 \\
\hline$\gamma \mathrm{C}=\mathrm{Oh}$ & 753 & 752 & 755 \\
\hline$\gamma \mathrm{C}-\mathrm{H} \mathrm{p}$ & 736 & 740 & 739 \\
\hline$\gamma \mathrm{C}-\mathrm{Hh}$ & $\sim 723$ & 727 & \\
\hline$\tau$ ring $h$ & 712 & & 719 \\
\hline$\tau$ ring $h$ & 689 & 680 & \\
\hline$\delta$ skeletal & 665 & 669 & \\
\hline$\delta$ ring $\mathrm{p}$ & 615 & 616 & 616 \\
\hline$\gamma \mathrm{C}=\mathrm{N} \mathrm{h}$ & 586 & & 591 \\
\hline$\tau$ ring $\mathrm{p}$ & 512 & & 504 \\
\hline
\end{tabular}

$\nu$, stretching; $\delta$, bending; $\gamma$, rocking; $\tau$, torsion; sym, symmetric; $p$, pyridine ring; $h$, Hückel-pyridine (aza-benzvalene) ring. See Table S4 for complete calculated spectra.

a Wavenumbers (scaled by 0.978 ) in $\mathrm{cm}^{-1}$.

b The approximate descriptions of the vibrations were made by examining the composition of the modes in terms of internal coordinates through their animation using a graphical interface. structure constraints, the number of relevant species reduces to 2 (!): forms $2 \mathrm{C}$ and $3 \mathrm{~A}$ in Fig. 3.

In Fig. 4(A and B), we compare the spectroscopic changes resulting from irradiation of the xenon matrix during $5 \mathrm{~h}$ with the calculated spectra for the Hückel pyridine containing forms $2 \mathrm{C}$ and $3 \mathrm{~A}$. There is a good general agreement between these spectra, allowing to conclude that, as predicted, $2 \mathrm{C}$ and $3 \mathrm{~A}$ are the main (if not the sole) photoproducts of $\alpha$-pyridil under the used experimental conditions. The proposed assignments for the bands given rise by the two observed photoproducts are provided in Table 2 . Table S4 gives the optimized geometries and full set of calculated frequencies and infrared intensities for these species. For 2C, 26 out of the 35 infrared bands predicted with intensities greater than $5 \mathrm{~km} \mathrm{~mol}^{-1}$ in the $500-1800 \mathrm{~cm}^{-1}$ region were observed experimentally (23 out of 34, in the case of $3 \mathrm{~A}$ ); see Table 2 and Table S4.

An interesting observation is the apparently similar amount of the two photoproducts obtained (see Fig. 4), in spite of the considerably higher relative energy of $2 \mathrm{C}$ compared to $3 \mathrm{~A}$. This result can, however, be promptly rationalized taking into account the findings of Zong et al. [62] that conical intersections are fundamental in driving the valence photoisomerization reactions of pyridine rings, which then take place partially in the ground-state potential energy surface. Indeed, the predicted energy barriers for conversion of pyridine into all its possible Hückel-type isomers, in the ground electronic state, were found to be similar, ranging from ca. 385 to about $420 \mathrm{~kJ} \mathrm{~mol}^{-1}(311-284 \mathrm{~nm})$ [62]. On the other hand, it can easily be assumed that the isomerization reactions of the pyridine rings of $\alpha$-pyridil leading to formation of $2 \mathrm{C}$ and $3 \mathrm{~A}$ do also have similar energy barriers [in particular because the valence isomerization rearrangement is localized in the side of the pyridine ring that is more distant from the substituent (see Fig. 3)], thus justify-
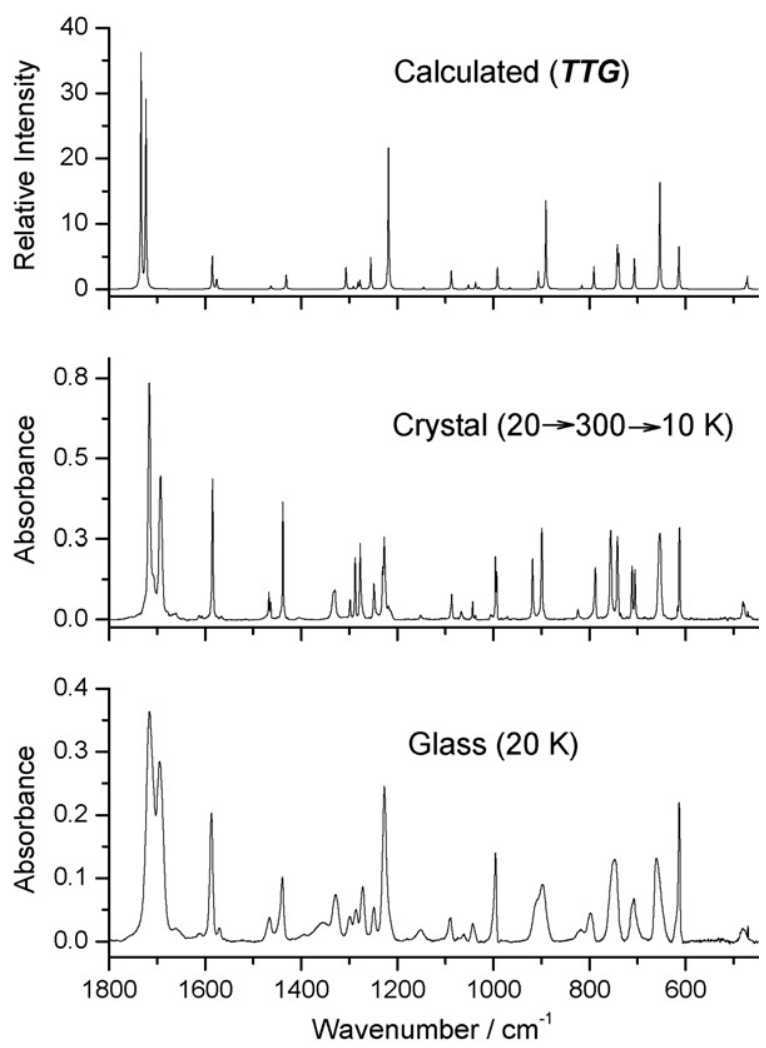

Fig. 5. Infrared spectra of $\alpha$-pyridil in the low temperature crystalline and glassy states (see Section 2 to detailed description of the experimental conditions) and the spectrum of the TTG conformer calculated at the DFT(B3LYP)/6-311++G(d,p) level of theory. 
ing the nearly equal amount of $2 \mathrm{C}$ and $3 \mathrm{~A}$ formed in the photolysis experiments.

\subsection{Infrared spectroscopy: $\alpha$-pyridil low temperature crystalline and glassy states}

Fig. 5 presents the infrared spectra of $\alpha$-pyridil in the neat low temperature amorphous phase and crystalline state, together with the calculated spectrum of the TTG conformer. The assignment of the recorded spectra is provided in Table 3.
As described in Section 2, the amorphous phase of the compound was prepared by deposition of its vapors directly onto the cold $(20 \mathrm{~K})$ CsI substrate of the cryostat. As expected, the spectrum of the amorphous phase is constituted by relatively wide bands, with maximum frequency values fitting nicely those calculated for the TTG conformer (in vacuum), which is the conformer present in the vapor prior to deposition of the solid layer. The crystal was obtained after heating the amorphous layer up to $250 \mathrm{~K}$. Subsequently, the CsI substrate was cooled down to $10 \mathrm{~K}$ and a new spectrum of the crystalline phase was collected. Compared with

Table 3

Observed frequencies of $\alpha$-pyridil in the low temperature crystalline and glassy states ${ }^{\mathrm{a}}$

\begin{tabular}{|c|c|c|c|c|c|c|c|}
\hline \multirow[t]{2}{*}{ Approximate description } & & \multicolumn{2}{|c|}{ Calculated } & \multicolumn{4}{|c|}{ Experimental $^{\mathrm{b}}$} \\
\hline & & $v$ & Intensity & Glass (20 K) & & Crystal (10 K) & \\
\hline$v(\mathrm{C}-\mathrm{H} 2) \mathrm{s}$ & $A$ & 3134.9 & 0.9 & 3112.8 & w & $3094.5 / 3083.0$ & w \\
\hline$\nu(\mathrm{C}-\mathrm{H} 2)$ as & $B$ & 3134.8 & 6.4 & & & & \\
\hline$\nu(\mathrm{C}-\mathrm{H} 3)$ as & $A$ & 3123.2 & 8.5 & 3061.1 & w & $3060.4 / 3048.6$ & w \\
\hline$\nu(\mathrm{C}-\mathrm{H} 3)$ as & $B$ & 3123.1 & 16.0 & & & & \\
\hline$\nu(\mathrm{C}-\mathrm{H} 4)$ as & $B$ & 3106.0 & 12.6 & 3056.6 & w & 3045.4 & sh \\
\hline$\nu(\mathrm{C}-\mathrm{H} 4) \mathrm{s}$ & $A$ & 3106.0 & 2.4 & & & & \\
\hline$v(\mathrm{C}-\mathrm{H} 1) \mathrm{s}$ & $A$ & 3087.1 & 11.3 & 3013.9 & $\mathrm{w}$ & 3013.6 & w \\
\hline$v(\mathrm{C}-\mathrm{H} 1)$ as & $B$ & 3087.0 & 14.6 & & & & \\
\hline$\nu(C=0) s$ & $A$ & 1733.8 & 225.8 & 1716.2 & $\mathrm{~S}$ & $1716.4 / 1708.2$ & $\mathrm{~S} / \mathrm{sh}$ \\
\hline$v(\mathrm{C}=\mathrm{O})$ as & $B$ & 1723.5 & 169.5 & 1694.7 & $\mathrm{~S}$ & 1693.0 & $\mathrm{~S}$ \\
\hline$v($ ring 3$)$ as & $B$ & 1585.2 & 9.2 & 1587.0 & $\mathrm{~m}$ & 1584.5 & $\mathrm{~S}$ \\
\hline$v($ ring 3$) \mathrm{s}$ & $A$ & 1585.2 & 22.3 & & & & \\
\hline$v($ ring 4$) \mathrm{s}$ & $A$ & 1577.1 & 5.3 & 1570.6 & w & 1565.9 & w \\
\hline$\nu($ ring 4$)$ as & $B$ & 1575.6 & 7.1 & & & & \\
\hline$\nu($ ring 6$) \mathrm{s} ; \delta(\mathrm{C}-\mathrm{H} 4) \mathrm{s}$ & $A$ & 1463.6 & 2.0 & 1465.7 & $\mathrm{~m}$ & $1467.6 / 1463.8$ & $\mathrm{~m} / \mathrm{m}$ \\
\hline$\delta(\mathrm{C}-\mathrm{H} 4)$ as; $\nu$ (ring 6$)$ as & $B$ & 1462.6 & 1.6 & & & & \\
\hline$\delta(\mathrm{C}-\mathrm{H} 3) \mathrm{s}$ & $A$ & 1434.3 & 0.7 & 1439.5 & $\mathrm{~m}$ & $1443.4 / 1438.3$ & $\mathrm{~m} / \mathrm{s}$ \\
\hline$\delta(\mathrm{C}-\mathrm{H} 3)$ as & $B$ & 1431.7 & 13.2 & & & & \\
\hline$v($ ring 5$) \mathrm{s}$ & $A$ & 1307.1 & 19.7 & 1328.5 & $\mathrm{~m}$ & $1333.4 / 1330.3$ & $\mathrm{sh} / \mathrm{m}$ \\
\hline$\nu$ (ring 5) as & $B$ & 1291.6 & 2.4 & 1299.3 & w & 1298.5 & w \\
\hline$\delta(\mathrm{C}-\mathrm{H} 4) \mathrm{s}$ & $A$ & 1282.1 & 6.1 & 1286.2 & $\mathrm{~m}$ & 1288.0 & $\mathrm{~m}$ \\
\hline$\nu($ ring 2$)$ as & $B$ & 1277.8 & 8.7 & 1272.1 & $\mathrm{~m}$ & 1277.6 & $\mathrm{~m}$ \\
\hline$\nu($ ring 2$) \mathrm{s} ; \nu($ ring 5$) \mathrm{s} ; \nu\left(\mathrm{C}-\mathrm{C}_{\alpha}\right) \mathrm{s}$ & $A$ & 1255.5 & 28.4 & 1248.9 & w & 1248.7 & w \\
\hline$v\left(\mathrm{C}-\mathrm{C}_{\alpha}\right)$ as & $B$ & 1218.7 & 131.2 & 1227.0 & $\mathrm{~m}$ & $1230.2 / 1227.4 / 1218.8$ & $\mathrm{~m} / \mathrm{m} / \mathrm{w}$ \\
\hline$\delta(\mathrm{C}-\mathrm{H} 2) \mathrm{s}$ & $A$ & 1145.7 & 1.0 & 1152.4 & $\mathrm{w}$ & 1151.7 & $\mathrm{w}$ \\
\hline$\delta(\mathrm{C}-\mathrm{H} 2)$ as & $B$ & 1145.2 & 0.9 & & & & \\
\hline$\nu($ ring 2$) \mathrm{s} ; \delta(\mathrm{C}-\mathrm{H} 3) \mathrm{s} ; \delta(\mathrm{C}-\mathrm{H} 1) \mathrm{s}$ & $A$ & 1088.6 & 1.3 & 1089.8 & $\mathrm{~m}$ & 1093.5 & sh \\
\hline$\nu($ ring 2$)$ as $; \delta(\mathrm{C}-\mathrm{H} 3)$ as $; \delta(\mathrm{C}-\mathrm{H} 1)$ as & $B$ & 1087.8 & 16.3 & & & 1087.0 & $\mathrm{~m}$ \\
\hline$v($ ring 6$) \mathrm{s} ; \nu(\mathrm{C}-\mathrm{C})$ & $A$ & 1052.3 & 4.4 & 1061.3 & $\mathrm{w}$ & 1067.7 & w \\
\hline$v$ (ring 6) as & $B$ & 1037.6 & 6.3 & 1043.4 & w & 1043.6 & w \\
\hline$v($ ring 6$) \mathrm{s} ; \nu(\operatorname{ring} 1) \mathrm{s}$ & $A$ & 1030.8 & 2.0 & & & 1037.8 & w \\
\hline$\gamma(\mathrm{C}-\mathrm{H} 3)$ as & $B$ & 996.6 & 0.1 & 996.0 & $\mathrm{~m}$ & $1006.7 / 1002.7$ & $\mathrm{w} / \mathrm{w}$ \\
\hline$\gamma(\mathrm{C}-\mathrm{H} 3) \mathrm{s}$ & $A$ & 996.1 & $<0.1$ & & & & \\
\hline$\nu(\operatorname{ring} 1) \mathrm{s} ; \delta(\operatorname{ring} 2) \mathrm{s}$ & $A$ & 992.2 & 0.1 & & & $996.1 / 993.4$ & $\mathrm{~m} / \mathrm{m}$ \\
\hline$\delta($ ring 2$)$ as; $v$ (ring 1$)$ as & $B$ & 991.9 & 19.9 & & & & \\
\hline$\gamma(\mathrm{C}-\mathrm{H} 4)$ as & $B$ & 966.1 & 1.2 & 975.4 & $\mathrm{~m}$ & $984.2 / 976.6 / 971.1$ & $\mathrm{w} / \mathrm{w} / \mathrm{w}$ \\
\hline$\gamma(\mathrm{C}-\mathrm{H} 4) \mathrm{s}$ & $A$ & 965.8 & 0.2 & & & & \\
\hline$\gamma(\mathrm{C}-\mathrm{H} 2)$ as & $B$ & 906.8 & 16.5 & 909.0 & $\mathrm{sh}$ & 918.8 & $\mathrm{~m}$ \\
\hline$\gamma(\mathrm{C}-\mathrm{H} 2) \mathrm{s}$ & $A$ & 904.8 & 0.2 & & & & \\
\hline Skeletal & $B$ & 891.0 & 80.3 & 897.8 & $\mathrm{~m}$ & $899.5 / 894.8$ & $\mathrm{~S} / \mathrm{m}$ \\
\hline$\tau($ ring 1$) s ; \gamma(C=0) s$ & $A$ & 816.2 & 3.5 & 798.6 & w & 788.1 & $\mathrm{~m}$ \\
\hline$\tau($ ring 1$)$ as; $\gamma(C=0)$ as & $B$ & 791.2 & 21.3 & 748.6 & $\mathrm{~m}$ & 756.2 & $\mathrm{~S}$ \\
\hline$\tau($ ring 1$)$ as; $\gamma(C=0)$ as & $A$ & 742.5 & 36.9 & & & 748.3 & sh \\
\hline$\gamma(\mathrm{C}-\mathrm{H} 1) \mathrm{s} ; \gamma(\mathrm{C}-\mathrm{H} 1)$ as; $\tau($ ring 3$)$ as & $B$ & 739.6 & 28.8 & 710.8 & sh & $741.9 / 735.8$ & $\mathrm{~S} / \mathrm{w}$ \\
\hline$\delta($ ring 1$) \mathrm{s}$ & $A$ & 732.4 & 0.4 & & & 722.3 & w \\
\hline$\delta($ ring 1$)$ as & $B$ & 707.2 & 11.7 & 707.9 & $\mathrm{~m}$ & 711.8 & $\mathrm{~m}$ \\
\hline$\tau($ ring 3$) s ; \gamma(C=0) s$ & $A$ & 706.7 & 18.2 & & & 705.5 & $\mathrm{~m}$ \\
\hline Skeletal & $B$ & 653.9 & 98.6 & 661.0 & $\mathrm{~m}$ & 654.1 & $\mathrm{~S}$ \\
\hline$\delta($ ring 3$) \mathrm{s}$ & $A$ & 617.9 & 0.2 & 613.4 & w & 617.0 & w \\
\hline$\delta($ ring 3 ) as & $B$ & 614.2 & 39.9 & & & 612.8 & $\mathrm{~S}$ \\
\hline Skeletal & $A$ & 474.8 & 4.4 & 470.3 & w & 470.8 & w \\
\hline$\tau($ ring 4$)$ as & $B$ & 472.0 & 11.3 & 480.3 & $\mathrm{~m}$ & $483.8 / 480.9 / 478.7 / 477.4$ & $\mathrm{w} / \mathrm{w} / \mathrm{w} / \mathrm{sh}$ \\
\hline$\tau($ ring 2$) \mathrm{s} ; \tau($ ring 4$) \mathrm{s}$ & $A$ & 422.5 & 1.9 & & & 422.0 & w \\
\hline$\tau($ ring 2$)$ as & $B$ & 422.1 & 9.2 & & & & \\
\hline$\tau($ ring 4$) s ; \tau($ ring 2$) s$ & $A$ & 399.4 & 1.5 & 408.5 & w & 408.5 & w \\
\hline$\tau($ ring 4$)$ as; $\tau($ ring 2 ) as & $B$ & 395.4 & 0.9 & 404.2 & w & 404.2 & w \\
\hline
\end{tabular}

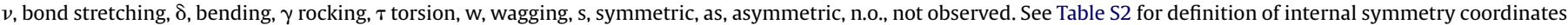

a Frequencies in $\mathrm{cm}^{-1}$, calculated intensities in $\mathrm{km} \mathrm{mol}^{-1}$.

b Experimental intensities are presented in qualitative terms: $\mathrm{S}=$ strong, $\mathrm{m}=$ medium, $\mathrm{w}=\mathrm{weak}$, $\mathrm{sh}=$ shoulder. 
the spectrum of the amorphous phase, the bands in the spectrum of the crystal are much narrower. However, the positions of the bands do not differ significantly in both spectra. Indeed, the spectrum of the crystal fits very well those obtained for the matrix-isolated compound and also that calculated for the TTG form. All these observations indicate that the intermolecular interactions in the solid state are rather weak in $\alpha$-pyridil, in consonance with its low melting point $154-156^{\circ} \mathrm{C}$ in comparison with isomeric compounds like, for example, $\left(2,2^{\prime}\right)$ bipyridinyl-4,4'-dicarbaldehyde $\left(188^{\circ} \mathrm{C}\right)$, 3-nitrocarbazole $\left(212-214^{\circ} \mathrm{C}\right), 4,7$-dihydroxy-1,10-phenanthroline $\left(>300^{\circ} \mathrm{C}\right)$ or 4 -amino-1,8-naphthalimide $\left(360^{\circ} \mathrm{C}\right)$ [71].

\section{Conclusion}

$\alpha$-Pyridil was, for the first time, isolated in low temperature noble gases (argon, xenon) matrices, and its molecular structure and vibrational signature probed by FTIR spectroscopy, supported by DFT(B3LYP)/6-311++G(d,p) calculations. Calculations predicted the existence of three different conformers (TTG, TCG and CCSk), all of them exhibiting skewed conformations around the intercarbonyl bond and the two $\mathrm{C}_{5} \mathrm{H}_{4} \mathrm{~N}-\mathrm{C}(=\mathrm{O})$ fragments nearly planar, and differing in the orientation of the pyridine rings relatively to the carbonyl groups. The $\mathbf{T T G}$ form was predicted to be the most stable conformer, accounting for more than $99 \%$ of the total population at $125^{\circ} \mathrm{C}$, whereas the two higher energy forms, TCG and CCSk were estimated theoretically to be, respectively, 21.0 and $35.1 \mathrm{~kJ} \mathrm{~mol}^{-1}$ higher in energy than the most stable form. Accordingly to these results, the TTG conformer was found to be the sole form of $\alpha$ pyridil present in the studied low temperature $\mathrm{Ar}$ and Xe matrices.

The TTG form was also found to be the unique conformer of $\alpha$ pyridil present in both the neat amorphous and crystalline phases of the compound. The IR spectra of the low temperature neat solid samples were found to match very closely those obtained for the matrix-isolated compound (and also with the calculated data for TTG), indicating that the intermolecular interactions in the solid state are rather weak in $\alpha$-pyridil.

Irradiation of matrix-isolated compound with UV light $(\lambda>235 \mathrm{~nm})$ led to its isomerization into unusual molecular species bearing a Hückel-type pyridine (aza-benzvalene) ring (forms $2 \mathrm{C}$ and 3A), which are structurally correlatable with the $\boldsymbol{T T G}$ conformer of $\alpha$-pyridil, in particular where the syn-periplanar arrangement of the $\mathrm{H}-\mathrm{C}-\mathrm{C}-\mathrm{C}=\mathrm{O}$ fragment is kept in order to preserve the stabilizing $\mathrm{CH} \ldots \mathrm{O}$ intramolecular $\mathrm{H}$-bond type interaction prevalent in the reactant species. The photochemical results obtained in the present study may also be considered relevant regarding the possibility of developing routes for preparative synthesis of Hückel-type pyridine containing molecules through UV irradiation of adequate pyridine containing precursors in cryogenic glasses.

\section{Acknowledgements}

This work was funded by Fundação para a Ciência e a Tecnologia (FCT), Portugal (POCTI/QUI/59019/2004 and POCTI/QUI/58937/2004), We also thank FCT(GRICES)/MinCyT for the award of a Collaborative Bilateral Research Grant. SL acknowledges FCT for the grant SFRH/BD/29698/2006. AGZ thanks ANPCyT (Project PICT/2006/0068).

\section{Appendix A. Supplementary data}

Supplementary data associated with this article can be found, in the online version, at doi:10.1016/j.jphotochem.2008.07.005.

\section{References}

[1] A. Gómez-Zavaglia, R. Fausto, J. Mol. Struct. 661-662 (2003) 195

[2] S. Lopes, A. Gómez-Zavaglia, L. Lapinski, N. Chattopadhayay, R. Fausto, J. Phys. Chem. A 108 (2004) 8256.

[3] S. Lopes, A. Gómez-Zavaglia, L. Lapinski, R. Fausto, J. Phys. Chem. A 109 (2005) 5560.

[4] S. Lopes, A. Gómez-Zavaglia, R. Fausto, Phys. Chem. Chem. Phys. 8 (2006) 1794.

[5] A.K. Sing, D.K. Palit, J. Mittal, Chem. Phys. Lett. 360 (2002) 443.

[6] A.K. Singh, D.K. Palit, Chem. Phys. Lett. 357 (2002) 173.

[7] A. Sarkar, S. Chakravorti, J. Lumin. 69 (1996) 161.

[8] M. Mizuno, K. Iwata, H. Takahashi, J. Mol. Struct. 661-662 (2003) 3.

[9] M. Pawlikowski, M. Zgierski, G. Orlandi, Chem. Phys. Lett. 105 (1984) 612.

[10] S. Bera, R. Mukherjee, M. Choudhury, J. Chem. Phys. 51 (1969) 754.

[11] D.S. Roy, K. Bhattacharyya, Chem. Phys. Lett. 69 (1980) 134.

[12] J. Arnett, S. McGlynn, J. Phys. Chem. 79 (1975) 626.

[13] J. Arnett, G. Newkome, W. Mattice, S. McGlynn, J. Am. Chem. Soc. 96 (1974) 4385.

[14] D.J. Morantz, A.J.C. Wright, J. Chem. Phys. 54 (1971) 692.

[15] A.M. Garcia, F.G. Benavides, T. Fletcher, E. Orts, Scand. J. Environ. Health 24 (6) (1998) 445.

[16] C.W. Ellwood, A.Ya. Tikhonov, Rhone Poulenc Agriculture (GB) and Novosib of Organic Chemistry (RU), Patent WO9803479 (1998).

[17] M.J. Robson, P.A. Worthington, ICI PLC (GB), Patent W09208714 (1992).

[18] M.A. Brodney, Pfizer Prod Inc. (US), Patent WO2006106416 (2006).

[19] R.A. Schnettler, W.D. Jones Jr., G.P. Claxton, Merrell Dow Pharma (US), Patent KR900000369B (1990).

[20] J. Fevig, J. Cacciola, C.G. Clark, Y.-S.L. Patrick, J.P.P. Donald, J.R. Pruitt, K.A. Rossi, Qi. Han, M. Quan, DU PONT Pharm Co. (US), Patent EA4515 (2004).

[21] D. Cheshire, D. Cladingboel, D. Hardern, M. Stocks, Astra Pharma Prod (GB), Patent HU9900143 (1999).

[22] J.W. Slater, D.M. D’Alessandro, F.R. Keene, P.J. Steel, Dalton Trans. (2006) 1954.

[23] R. López, D. Boys, B. Loeb, F. Zuloaga, J. Chem. Perkin Trans. 2 (1998) 877.

[24] D.F. Colton, W.J. Geary, J. Chem. Soc. Dalton Trans. 4 (1972) 547

[25] B.I. Ita, O.E. Offiong, Mater. Chem. Phys. 51 (1997) 203.

[26] S. Hirokawa, T. Ashida, Acta Crystallogr. 14 (1961) 774.

[27] T. Ashida, S. Hirokawa, Acta Crystallogr. B26 (1970) 454.

[28] R.W. Le Fèvre, P.J. Stiles, J. Chem. Soc. B (1966) 420.

[29] I. Bernal, Nature 200 (1963) 1318.

[30] H. Sterk, Monatsh. Chem. 99 (1968) 999

[31] T. Kolev, J. Mol. Struct. 349 (1995) 381.

[32] T. Kolev, P. Bleckmann, Spectrosc. Lett. 23 (1990) 1331

[33] P. Migchels, G. Maes, Th. Zeegers-Huyskens, M. Rospenk, J. Mol. Struct. 193 (1989) 223.

[34] V. Háda, A. Tungler, L. Szepesy, J. Catal. 209 (2002) 472.

[35] H. Inoue, K. Nagaya, J. Chem. Soc. Perkin Trans. 2 (10) (1983) 1581.

[36] H. Inoue, T. Sakurai, T. Hoshi, J. Okubo, J. Photochem. Photobiol. A: Chem. 72 (1993) 41.

[37] H. Inoue, T. Sakurai, T. Hoshi, J. Okubo, J. Photochem. Photobiol. A: Chem. 60 (1991) 121.

[38] S. Bera, R. Mukherjee, D. Mukherjee, M. Choudhury, J. Chem. Phys. 55 (1971) 5826.

[39] T.R. Evans, P.A. Leermakers, J. Am. Chem. Soc. 89 (1967) 4380.

[40] J. Barassin, Ann. Chim. 8 (1963) 637.

[41] N. Yamada, M. Hasegawa, K. Kumagai, S. Enomoto, H. Horiuchi, T. Yoshinaga, H. Hiratsuka, M. Kobayashi, T. Hoshi, Bull. Chem. Soc. Jpn. 78 (2005) 1018.

[42] M.J. Frisch, G.W. Trucks, H.B. Schlegel, G.E. Scuseria, M.A. Robb, J.R. Cheeseman, J. Montgomery, J.A., T. Vreven, K.N. Kudin, J.C. Burant, J.M. Millam, S.S. Iyengar, J. Tomasi, V. Barone, B. Mennucci, M. Cossi, G. Scalmani, N. Rega, G.A. Petersson, H. Nakatsuji, M. Hada, M. Ehara, K. Toyota, R. Fukuda, J. Hasegawa, M. Ishida, T. Nakajima, Y. Honda, O. Kitao, H. Nakai, M. Klene, X. Li, J.E. Knox, H.P. Hratchian, J.B. Cross, V. Bakken, C. Adamo, J. Jaramillo, R. Gomperts, R.E. Stratmann, O. Yazyev, A.J. Austin, R. Cammi, C. Pomelli, J.W. Ochterski, P.Y. Ayala, K. Morokuma, G.A. Voth, P. Salvador, J.J. Dannenberg, V.G. Zakrzewski, S. Dapprich, A.D. Daniels, M.C. Strain, O. Farkas, D.K. Malick, A.D. Rabuck, K. Raghavachari, J.B. Foresman, J.V. Ortiz, Q. Cui, A.G. Baboul, S. Clifford, J. Cioslowski, B.B. Stefanov, G. Liu, A. Liashenko, P. Piskorz, I. Komaromi, R.L. Martin, D.J. Fox, T. Keith, M.A. Al-Laham, C.Y. Peng, A. Nanayakkara, M. Challacombe, P.M. W. Gill, B. Johnson, W. Chen, M.W. Wong, C. Gonzalez, J.A. Pople. Gaussian 03, Revision C.02, Gaussian, Inc., Wallingford, CT, 2004.

[43] A.D. Becke, Phys. Rev. A. 38 (1988) 3098.

[44] C.T. Lee, W.T. Yang, R.G. Parr, Phys. Rev. B 37 (1988) 785.

[45] P. Császár, P. Pulay, J. Mol. Struct. (Theochem.) 114 (1984) 31.

[46] J.H. Schachtschneider, Technical Report, Shell Development Co., Emeryville, CA, 1969.

[47] N.J. Turro, Modern Molecular Photochemistry, The Benjamin/Cummings Publishing Co., Inc., 1978

[48] B.P. Stoicheff, Can. J. Phys. 32 (1954) 339.

[49] F. Mata, M.J. Quintana, G.O. Sørensen, J. Mol. Struct. 42 (1977) 1.

[50] S. Breda, L. Lapinski, I. Reva, R. Fausto, J. Photochem. Photobiol. A 162 (2004) 139.

[51] S. Breda, I.D. Reva, L. Lapinski, R. Fausto, Phys. Chem. Chem. Phys. 6 (2004) 929.

[52] S. Breda, I.D. Reva, L. Lapinski, L. Frija, M.L. Cristiano, R. Fausto, J. Phys. Chem. A 110 (2006) 6415. 
[53] I.D. Reva, M.J. Nowak, L. Lapinski, R. Fausto, Chem. Phys. Lett 452 (2008) 20.

[54] O.L. Chapman, C.L. McIntosh, J. Pacansky, J. Am. Chem. Soc. 95 (1993) 614

[55] D.E. Johnstone, J.R. Sodeau, J. Phys. Chem. 95 (1991) 165.

[56] S. Kudoh, M. Takayanagi, M. Nakata, J. Photochem. Photobiol. A 123 (1999) 25.

[57] U. Hees, U.-J. Vogelbacher, G. Michela, M. Regitz, Tetrahedron 45 (1989) 3115

[58] S. Kudoh, M. Takayanagi, M. Nakata, Chem. Phys. Lett. 322 (2000) 363.

[59] M.G. Barlow, R. Barlow, R.N. Haszeldine, J.G. Dingwall, J. Chem. Soc. Perkin Trans. I (1973) 1542.

[60] R.D. Chambers, R. Middleton, R.P. Corbally, J. Chem. Soc. Chem. Commun. (1975) 731, ibidim (1977) 154.

[61] K.E. Wilzbach, D.J. Raush, J. Am. Chem. Soc. 92 (1970) 2178.

[62] D. Zhong, E.W.-G. Diau, T.M. Bernhardt, S. De Feyter, J.D. Roberts, A.H. Zewail, Chem. Phys. Lett. 298 (1998) 129.
[63] I. Yavari, S. Moradi, H.K. Fard, F. Mourmohammadian, D. Tahmassebi, Theochem. 578 (2002) 249.

[64] U.D. Priyakumar, T.C. Dinadayalane, G.N. Sastry, Chem. Phys. Lett. 337 (2001) 361.

[65] R. Liu, X. Zhou, P. Pulay, J. Phys. Chem. 96 (1992) 3669

[66] H. Abe, K.M.T. Yamada, Struct. Chem. 14 (2003) 211.

[67] H. Dubost, Chem. Phys. 12 (1976) 139.

[68] A.D. Abbate, C.B. Moore, J. Chem. Phys. 82 (1985) 1255

[69] E. Sánchez-García, A. Mardyukov, A. Tekin, R. Crespo-Otero, L.A. Montero, W. Sander, G. Jansen, Chem. Phys. 343 (2008) 168.

[70] R.G.S. Pong, B.S. Huang, J. Laureni, A. Krantz, J. Am. Chem. Soc. 99 (1977) 4153.

[71] Sigma-Aldrich online Catalog 2008. http://www.sigmaaldrich.com. 